Click here to view linked References

\title{
Synthesis, leishmanicidal, trypanocidal and cytotoxic activities of quinoline-chalcone and quinoline-chromone hybrids
}

\author{
Juan C. Coa ${ }^{1}$. Elisa García ${ }^{1}$. Miguel Carda ${ }^{2}$. Raúl Agut ${ }^{2}$. Iván D. Vélez ${ }^{3}$. July A. Muñoz ${ }^{3}$ Lina M. \\ Yepes $^{3}$ Sara M. Robledo ${ }^{3}$. Wilson I. Cardona ${ }^{1}$ \\ 1 Chemistry of Colombian Plants, Institute of Chemistry, Exact and Natural Sciences School, \\ University of Antioquia-UdeA, Calle 70 No. 52-21, A.A 1226, Medellín, Colombia \\ ${ }^{2}$ Department of Inorganic and Organic Chemistry, Jaume I University, E-12071 Castellón, Spain \\ ${ }^{3}$ PECET-Medical Research Institute, School of Medicine, University of Antioquia-UdeA. Calle 70 No. \\ 52-21, A.A 1226 Medellín, Colombia
}


*Corresponding authors: E-mail address:

\author{
Wilson I. Cardona \\ wilson.cardona1@udea.edu.co \\ phone: $+574-2195653$ \\ Fax: $+57-42330120$ \\ Sara M. Robledo \\ sara.robledo@udea.edu.co \\ phone: +574-2196503 \\ Fax: +574-2196511
}




\begin{abstract}
We report herein the synthesis and biological activities (cytotoxicity, leishmanicidal and trypanocidal) of six quinoline-chalcone and five quinoline-chromone hybrids. The synthesized compounds were evaluated against amastigotes forms of $L .(V)$ panamensis which is the most prevalent Leishmania species in Colombia and Trypanosoma cruzi which is the major pathogenic species to humans. Cytotoxicity was evaluated against human U-937 macrophages. Compounds 8-12, 20, 23 and 24 showed activity against $L .(V)$ panamensis while compounds $9,10,12,20$ and 23 had activity against $T$. cruzi with $\mathrm{EC}_{50}$ values lower than $18 \mathrm{mg} / \mathrm{Ml} .20$ was the most active compound for both $L$. (V) panamensis and $T$. cruzi with $\mathrm{EC}_{50}$ of $6.11 \pm 0.26 \mu \mathrm{g} / \mathrm{mL}(16.91 \mu \mathrm{M})$ and $4.09 \pm 0.24(11.32 \mu \mathrm{M})$, respectively. All hybrids compounds showed better activity than the anti-leishmanial drug meglumine antimoniate. Compounds $\mathbf{2 0}$ and $\mathbf{2 3}$ showed higher actives than benznidazole, the current antitrypanosomal drug. Although these compounds showed toxicity for mammalian U-937 cells, still have potential to be considered as candidates to antileishmanial or trypanocydal drug development.
\end{abstract}

Keywords: leishmaniasis; Chagas disease; antiprotozoal activity; cytotoxicity; quinoline; chalcone; chromone; hybrids 


\section{Introduction}

Neglected tropical diseases (NTD) are a cause of mortality in various developing countries of tropical and subtropical regions. These diseases are significant health problems in endemic countries, affecting more than one billion people worldwide (WHO, 2013). This situation is aggravated by increasing treatment failures with available drugs (Bhutta et al., 2014). NTD include, among others, Chagas' disease (American trypanosomiasis) and leishmaniasis. These are parasitic diseases caused by the parasitic protozoan Trypanosoma cruzi (T. cruzi) and Leishmania species. These diseases affect more than 10 million people worldwide (Alvar et al., 2012; Nouvellet et al., 2015) L. (V) panamensis is one of the most prevalent Leishmania species involved in human cases of cutaneous leishmaniasis in Colombia (Alvar et al., 2012). Current chemotherapies are based on old drugs, pentavalent antimonials (meglumine antimoniate and sodium stibogluconate) to treat cutaneous leishmaniasis and nitroaromatic compounds (benznidazole and nifurtimox) for treatment of Chagas disease. Unfortunatelly, all of these drugs are not very effective in the chronic phase and have toxicity, side effects and parasite resistance (Den Boer et al., 2011; Keenan et al., 2015; Chatelain et al., 2011).

A quinolinic core is a structural feature of several bioactive compounds. Thus, this core is an interesting constituent for new drugs design. Anti-mycobacterial, anti-microbial, anti-convulsant, antiinflamatory, anti-tumoral, cardiovascular but also leishmanicidal and trypanocidal, are some biological activities exhibited by compounds having this heteroaromatic ring (Suresh et al., 2009; Nakayama et al., 2005; Tempone et al., 2005; Dietze et al., 2001; Mohammed et al., 2003; Vieira et al., 2008; Cardona et al., 2013; Palit et al., 2009; Franck et al., 2004; Coa et al., 2015). The antileishmanial activity of several chalcones has been reported (Kayser et al., 2001; Liu et al., 2003; Boeck et al., 2006). The most promising of this class of compounds is licochalcone $A$, an oxygenated chalcone 
isolated from the roots of the Chinese plant Glycyrrhiza spp, which inhibits the fumarate reductase, a selective target present in the mitochondria of the parasite (Chen et al., 2001). Similarly, chromones are important classes of compounds having versatile biological activities (Horton et al., 2003; Hadjeri et al., 2003; Ellis et al., 1972; Houghton et al., 2000; Mallick et al., 2011; Baloch et al., 2012). Both moieties are well known for their antiprotozoal activity. Some synthetic chromones were effective against L. (L) donovani (Mallick et al., 2011) and L. (L) major (Baloch et al., 2012) in in vivo studies.

In the search for new therapeutic alternatives to treat cutaneous leishmaniasis and Chagas disease, in this work we designed and synthesized a series of quinoline-chalcone and quinoline-chromone hybrids and evaluated in vitro their cytotoxicity, leishmanicidal and trypanocidal activities.

\section{Material and Methods}

Chemistry

\section{General remarks}

Microwave reactions were carried out in a CEM Discover microwave reactor in sealed vessels (monowave, maximum power $300 \mathrm{~W}$, temperature control by IR sensor, fixed temperature). ${ }^{1} \mathrm{H}$ and ${ }^{13} \mathrm{C}$ NMR spectra were recorded on a Varian instrument operating at 500 and $125 \mathrm{MHz}$, respectively. The signals of the deuterated solvent $\left(\mathrm{CDCl}_{3}\right)$ were used as reference (the singlet at $\delta=7.27 \mathrm{ppm}$ for ${ }^{1} \mathrm{H}$ NMR and the triplet centred at $\delta=77.00$ ppm for ${ }^{13} \mathrm{C}$ NMR $)$. Carbon atom types $\left(\mathrm{C}, \mathrm{CH}, \mathrm{CH}_{2}, \mathrm{CH}_{3}\right)$ were determined by using the DEPT or APT pulse sequence. High resolution mass spectra were recorded using electrospray ionization mass spectrometry (ESI-MS). A QTOF Premier instrument with an orthogonal Z-spray-electrospray interface (Waters, Manchester, UK) was used operating in the 
$\mathrm{W}$-mode. The drying and cone gas was nitrogen set to flow rates of 300 and $30 \mathrm{~L} / \mathrm{h}$, respectively. Methanol sample solutions (ca. $1 \times 10^{-5} \mathrm{M}$ ) were directly introduced into the ESI spectrometer at a flow rate of $10 \mu \mathrm{L} / \mathrm{min}$. A capillary voltage of $3.5 \mathrm{kV}$ was used in the positive scan mode, and the cone voltage set to $U \mathrm{c}=10 \mathrm{~V}$. For accurate mass measurements, a $2 \mathrm{mg} / \mathrm{L}$ standard solution of leucine enkephalin was introduced via the lock spray needle at a cone voltage set to $85 \mathrm{~V}$ and a flow rate of $30 \mu \mathrm{L} / \mathrm{min}$. IR spectra were recorded on a Spectrum RX I FT-IR system (Perkin-Elmer, Waltham, MA, USA) in KBr disks. Silica gel 60 (0.063-0.200 mesh, Merck, Whitehouse Station, NJ, USA) was used for column chromatography, and precoated silica gel plates (Merck 60 F254 $0.2 \mathrm{~mm}$ ) were used for thin layer chromatography (TLC).

\section{General procedure for the synthesis of bromoalkyl derivatives}

Quinoline or chromone $(1 \mathrm{mmol})$, potassium hydroxide $(1.5 \mathrm{mmol}, 84.2 \mathrm{mg})$ and acetonitrile (10 $\mathrm{mL}$ ), were placed in a $25 \mathrm{~mL}$ flat-bottomed flask equipped with a magnetic stirring bar. The mixture was stirred and heated to reflux for a period of $5 \mathrm{~min}$, under microwave irradiation. Then, 1, $\omega$ dibromoalkane $(1.1 \mathrm{mmol})$ was added to the reaction mixture which was refluxed for 30 minutes $(70$ W). The crude reaction mixture was concentrated on a rotatory evaporator and the residue was purified by column chromatography over silica gel eluting with hexane and a mixture of hexane-ethyl acetate (9:1 ratio) to obtain bromoalkyl derivatives in yields ranging between $42-80 \%$. Monitoring of the reaction progress and product purification was carried out by TLC. 
8-(3-bromopropoxy)quinoline (2): Yield 75\% (0.75 mmol, $200 \mathrm{mg})$; brown oil. IR $\left(\mathrm{cm}^{-1}\right): v_{\max } 1570$ $\left(\mathrm{C}=\mathrm{C}_{\mathrm{Ar}}\right), 1500(\mathrm{C}=\mathrm{N}), 1263(\mathrm{C}-\mathrm{O}-\mathrm{C}), 794\left(\mathrm{C}-\mathrm{H}_{\mathrm{Ar}}\right) .{ }^{1} \mathrm{H}-\mathrm{NMR}\left(\mathrm{CDCl}_{3}\right): \delta 2.20-2.30(2 \mathrm{H}, \mathrm{m}), 4.03(2 \mathrm{H}$, t, $J=5.3 \mathrm{~Hz}), 4.47(2 \mathrm{H}, \mathrm{t}, J=5.6 \mathrm{~Hz}), 7.21(1 \mathrm{H}, \mathrm{d}, J=6.2 \mathrm{~Hz}), 7.44-7.56(3 \mathrm{H}, \mathrm{m}), 8.20(1 \mathrm{H}, \mathrm{dd}, J=$ 8.3, $1.5 \mathrm{~Hz}), 8.94(1 \mathrm{H}, \mathrm{dd}, J=4.2,1.5 \mathrm{~Hz}) .{ }^{13} \mathrm{C}-\mathrm{NMR}\left(\mathrm{CDCl}_{3}\right): \delta 30.0\left(\mathrm{CH}_{2}\right), 31.9\left(\mathrm{CH}_{2}\right), 69.6\left(\mathrm{CH}_{2}\right)$, 111.6 (C), 120.6 (C), 121.7 (C), 126.8 (C), 129.6 (C), 136.2 (C), 140.7 (C), 149.4 (C), 154.8 (C).

8-(4-bromobutoxy)quinoline (3): Yield 64\% (0.64 mmol, $179 \mathrm{mg})$; dark yellow solid, M.p. 46-48 ${ }^{\circ} \mathrm{C}$. IR $\left(\mathrm{cm}^{-1}\right): v_{\max } 1593\left(\mathrm{C}=\mathrm{C}_{\mathrm{Ar}}\right), 1529(\mathrm{C}=\mathrm{N}), 1240(\mathrm{C}-\mathrm{O}-\mathrm{C}), 835\left(\mathrm{C}-\mathrm{H}_{\mathrm{Ar}}\right) .{ }^{1} \mathrm{H}-\mathrm{NMR}\left(\mathrm{CDCl}_{3}\right): \delta 2.17-2.27$ $(4 \mathrm{H}, \mathrm{m}), 3.57(2 \mathrm{H}, \mathrm{t}, J=5.8 \mathrm{~Hz}), 4.29(2 \mathrm{H}, \mathrm{t}, J=5.5 \mathrm{~Hz}), 7.09(1 \mathrm{H}, \mathrm{d}, J=7.5 \mathrm{~Hz}), 7.39-7.53(3 \mathrm{H}, \mathrm{m})$, $8.17(1 \mathrm{H}, \mathrm{dd}, J=8.3,1.1 \mathrm{~Hz}), 9.01(1 \mathrm{H}, \mathrm{dd}, J=4.2,1.3 \mathrm{~Hz}) \cdot{ }^{13} \mathrm{C}-\mathrm{NMR}\left(\mathrm{CDCl}_{3}\right): \delta 27.7\left(\mathrm{CH}_{2}\right), 29.5$ $\left(\mathrm{CH}_{2}\right), 33.7\left(\mathrm{CH}_{2}\right), 67.8\left(\mathrm{CH}_{2}\right), 108.8(\mathrm{C}), 119.7(\mathrm{C}), 121.7(\mathrm{C}), 126.8(\mathrm{C}), 129.6(\mathrm{C}), 136.3(\mathrm{C}), 139.9$ (C), $149.2(\mathrm{C}), 154.5(\mathrm{C})$.

8-((5-bromopentyl)oxy) quinoline (4): Yield 51\% (0.51 mmol, $150 \mathrm{mg})$; brown solid, M.p. $58-62^{\circ} \mathrm{C}$. IR $\left(\mathrm{cm}^{-1}\right): v_{\max } 1595\left(\mathrm{C}=\mathrm{C}_{\mathrm{Ar}}\right), 1529(\mathrm{C}=\mathrm{N}), 1288(\mathrm{C}-\mathrm{O}-\mathrm{C}), 829\left(\mathrm{C}-\mathrm{H}_{\mathrm{Ar}}\right) .{ }^{1} \mathrm{H}-\mathrm{NMR}\left(\mathrm{CDCl}_{3}\right): \delta 1.69-1.82$ $(2 \mathrm{H}, \mathrm{m}), 1.97-2.07(2 \mathrm{H}, \mathrm{m}), 2.07-2.19(2 \mathrm{H}, \mathrm{m}), 3.50(2 \mathrm{H}, \mathrm{t}, J=6.8 \mathrm{~Hz}), 4.29(2 \mathrm{H}, \mathrm{t}, J=6.8 \mathrm{~Hz}), 7.10$ $(1 \mathrm{H}, \mathrm{d}, J=7.5 \mathrm{~Hz}), 7.40-7.53(3 \mathrm{H}, \mathrm{m}), 8.17(1 \mathrm{H}, \mathrm{dd}, J=8.2,1.0 \mathrm{~Hz}), 8.99(1 \mathrm{H}, \mathrm{dd}, J=4.2,1.0 \mathrm{~Hz})$. ${ }^{13} \mathrm{C}-\mathrm{NMR}\left(\mathrm{CDCl}_{3}\right): \delta 24.9\left(\mathrm{CH}_{2}\right), 28.2\left(\mathrm{CH}_{2}\right), 32.6\left(\mathrm{CH}_{2}\right), 33.6\left(\mathrm{CH}_{2}\right), 68.6\left(\mathrm{CH}_{2}\right), 108.7(\mathrm{C}), 119.6$ (C), 121.6 (C), 126.7 (C), 129.6 (C), 136.0 (C), 140.3 (C), 149.4 (C), 154.7 (C).

8-((8-bromooctyl)oxy) quinoline (5): Yield $80 \%(0.80 \mathrm{mmol}, 269 \mathrm{mg})$; light brown oil. IR $\left(\mathrm{cm}^{-1}\right): v_{\max }$ $1593\left(\mathrm{C}=\mathrm{C}_{\mathrm{Ar}}\right), 1529(\mathrm{C}=\mathrm{N}), 1286(\mathrm{C}-\mathrm{O}-\mathrm{C}), 831\left(\mathrm{C}-\mathrm{H}_{\mathrm{Ar}}\right) .{ }^{1} \mathrm{H}-\mathrm{NMR}\left(\mathrm{CDCl}_{3}\right): \delta 1.33-1.50(6 \mathrm{H}, \mathrm{m}), 1.51-$ $1.64(2 \mathrm{H}, \mathrm{m}), 1.81-1.94(2 \mathrm{H}, \mathrm{m}), 1.99-2.11(2 \mathrm{H}, \mathrm{m}), 3.42(2 \mathrm{H}, \mathrm{t}, J=6.9 \mathrm{~Hz}), 4.25(2 \mathrm{H}, \mathrm{t}, J=6.9 \mathrm{~Hz})$, $7.08(1 \mathrm{H}, \mathrm{d}, J=7.6 \mathrm{~Hz}), 7.36-7.52(3 \mathrm{H}, \mathrm{m}), 8.15(1 \mathrm{H}, \mathrm{dd}, J=8.3,1.5 \mathrm{~Hz}), 8.99(1 \mathrm{H}, \mathrm{dd}, J=4.2,1.6$ Hz). ${ }^{13} \mathrm{C}-\mathrm{NMR}\left(\mathrm{CDCl}_{3}\right): \delta 26.0\left(\mathrm{CH}_{2}\right), 28.1\left(\mathrm{CH}_{2}\right), 28.7\left(\mathrm{CH}_{2}\right), 29.0\left(\mathrm{CH}_{2}\right), 29.3\left(\mathrm{CH}_{2}\right), 32.8\left(\mathrm{CH}_{2}\right)$, $34.1\left(\mathrm{CH}_{2}\right), 68.9\left(\mathrm{CH}_{2}\right), 108.8(\mathrm{C}), 119.4(\mathrm{C}), 121.6(\mathrm{C}), 126.8(\mathrm{C}), 129.5(\mathrm{C}), 136.1(\mathrm{C}), 140.2(\mathrm{C})$, $149.2(\mathrm{C}), 154.8(\mathrm{C})$. 
8-((9-bromononyl)oxy)quinoline (6): Yield 75\% (0.75 mmol, $263 \mathrm{mg})$; light brown oil. IR $\left(\mathrm{cm}^{-1}\right): v_{\max }$ $1595\left(\mathrm{C}=\mathrm{C}_{\mathrm{Ar}}\right), 1531(\mathrm{C}=\mathrm{N}), 1286(\mathrm{C}-\mathrm{O}-\mathrm{C}), 833\left(\mathrm{C}-\mathrm{H}_{\mathrm{Ar}}\right) .{ }^{1} \mathrm{H}-\mathrm{NMR}\left(\mathrm{CDCl}_{3}\right): \delta 1.31-1.52(6 \mathrm{H}, \mathrm{m}), 1.52-$ $1.66(2 \mathrm{H}, \mathrm{m}), 1.82-1.95(2 \mathrm{H}, \mathrm{m}), 2.00-2.13(2 \mathrm{H}, \mathrm{m}), 3.44(2 \mathrm{H}, \mathrm{t}, J=6.9 \mathrm{~Hz}), 4.26(2 \mathrm{H}, \mathrm{t}, J=6.9 \mathrm{~Hz})$, $7.10(1 \mathrm{H}, \mathrm{d}, J=7.6 \mathrm{~Hz}), 7.38-7.53(3 \mathrm{H}, \mathrm{m}), 8.18(1 \mathrm{H}, \mathrm{dd}, J=8.3,1.3 \mathrm{~Hz}), 9.02(1 \mathrm{H}, \mathrm{dd}, J=4.2,1.3$ Hz). ${ }^{13} \mathrm{C}-\mathrm{NMR}\left(\mathrm{CDCl}_{3}\right): \delta 26.1\left(\mathrm{CH}_{2}\right), 28.2\left(\mathrm{CH}_{2}\right), 28.7\left(\mathrm{CH}_{2}\right), 29.0\left(\mathrm{CH}_{2}\right), 29.4\left(\mathrm{CH}_{2}\right)(\mathrm{x} 2), 32.8$ $\left(\mathrm{CH}_{2}\right), 34.1\left(\mathrm{CH}_{2}\right), 69.0\left(\mathrm{CH}_{2}\right), 108.6(\mathrm{C}), 119.3(\mathrm{C}), 121.6(\mathrm{C}), 126.8(\mathrm{C}), 129.5(\mathrm{C}), 136.2(\mathrm{C}), 140.0$ (C), $149.2(\mathrm{C}), 154.8(\mathrm{C})$.

8-((12-bromododecyl)oxy)quinoline (7): Yield 67\% (0.67 mmol, $263 \mathrm{mg})$; brown solid, M.p. 44-46 ${ }^{\circ} \mathrm{C}$. IR $\left(\mathrm{cm}^{-1}\right): v_{\max } 1597\left(\mathrm{C}=\mathrm{C}_{\mathrm{Ar}}\right), 1529(\mathrm{C}=\mathrm{N}), 1259(\mathrm{C}-\mathrm{O}-\mathrm{C}), 829\left(\mathrm{C}-\mathrm{H}_{\mathrm{Ar}}\right) .{ }^{1} \mathrm{H}-\mathrm{NMR}\left(\mathrm{CDCl}_{3}\right): \delta 1.23-$ $1.38(6 \mathrm{H}, \mathrm{m}), 1.37-1.49(2 \mathrm{H}, \mathrm{m}), 1.49-1.62(2 \mathrm{H}, \mathrm{m}), 1.79-1.93(2 \mathrm{H}, \mathrm{m}), 1.98-2.12(2 \mathrm{H}, \mathrm{m}), 3.42(2 \mathrm{H}, \mathrm{t}$, $J=6.9 \mathrm{~Hz}), 4.25(2 \mathrm{H}, \mathrm{t}, J=7.0 \mathrm{~Hz}), 7.07(1 \mathrm{H}, \mathrm{d}, J=7.5 \mathrm{~Hz}), 7.35-7.51(3 \mathrm{H}, \mathrm{m}), 8.13(1 \mathrm{H}, \mathrm{dd}, J=8.3$, $1.2 \mathrm{~Hz}), 8.98(1 \mathrm{H}, \mathrm{dd}, J=4.2,1.2 \mathrm{~Hz}) .{ }^{13} \mathrm{C}-\mathrm{NMR}\left(\mathrm{CDCl}_{3}\right): \delta 26.1\left(\mathrm{CH}_{2}\right), 28.2\left(\mathrm{CH}_{2}\right), 28.8\left(\mathrm{CH}_{2}\right), 29.0$ $\left(\mathrm{CH}_{2}\right), 29.6\left(\mathrm{CH}_{2}\right)(\mathrm{x} 3), 29.5\left(\mathrm{CH}_{2}\right), 29.4\left(\mathrm{CH}_{2}\right)(\mathrm{x} 2), 32.9\left(\mathrm{CH}_{2}\right), 34.1\left(\mathrm{CH}_{2}\right), 69.0\left(\mathrm{CH}_{2}\right), 108.6(\mathrm{C})$, 119.3 (C), 121.5 (C), 126.8 (C), 129.5 (C), 136.0 (C), 140.3 (C), 149.2 (C), 154.9 (C).

7-[(9-bromononyl)oxy]-4H-chromen-4-one (18): Yield 49\% (0.49 mmol, $180 \mathrm{mg})$; light yellow solid, M.p. $60-62^{\circ} \mathrm{C}$. IR $\left(\mathrm{cm}^{-1}\right)$ : $v_{\max } 1649(\mathrm{C}=\mathrm{O}), 1602(\mathrm{C}=\mathrm{C}), 1444\left(\mathrm{C}=\mathrm{C}_{\mathrm{Ar}}\right), 1234(\mathrm{C}-\mathrm{O}-\mathrm{C}), 813\left(\mathrm{C}-\mathrm{H}_{\mathrm{Ar}}\right)$. ${ }^{1} \mathrm{H}-\mathrm{NMR}\left(\mathrm{CDCl}_{3}\right): \delta$ 1.28-1.42 (10H, m), 1.42-1.55 (2H, m), 1.78-1.93 (2H, m), $3.43(2 \mathrm{H}, \mathrm{t}, J=6.8$ $\mathrm{Hz}), 4.05(2 \mathrm{H}, \mathrm{t}, J=6.5 \mathrm{~Hz}), 6.29(1 \mathrm{H}, \mathrm{d}, J=6.0 \mathrm{~Hz}), 6.83(1 \mathrm{H}, \mathrm{d}, J=2.3 \mathrm{~Hz}), 6.97(1 \mathrm{H}, \mathrm{dd}, J=9.0$, $2.3 \mathrm{~Hz}), 7.80(1 \mathrm{H}, \mathrm{d}, J=6.1 \mathrm{~Hz}), 8.11(1 \mathrm{H}, \mathrm{d}, J=9.0 \mathrm{~Hz}) .{ }^{13} \mathrm{C}-\mathrm{NMR}\left(\mathrm{CDCl}_{3}\right): \delta 25.9\left(\mathrm{CH}_{2}\right), 28.1$ $\left(\mathrm{CH}_{2}\right), 28.7\left(\mathrm{CH}_{2}\right), 28.9\left(\mathrm{CH}_{2}\right), 29.2\left(\mathrm{CH}_{2}\right), 29.3\left(\mathrm{CH}_{2}\right), 32.8\left(\mathrm{CH}_{2}\right), 34.1\left(\mathrm{CH}_{2}\right), 68.7\left(\mathrm{CH}_{2}\right), 100.8(\mathrm{C})$, 112.9 (C), 114.9 (C), 118.6 (C), 127.1 (C), 154.9 (C), 158.3 (C), 163.7 (C), $177.1(\mathrm{C}=\mathrm{O})$. 
7-[(12-bromododecyl)oxy]-4H-chromen-4-one (19): Yield 42\% (0.42 mmol, $172 \mathrm{mg})$; light yellow solid, M.p. 58-60 C. IR ( $\left.\mathrm{cm}^{-1}\right): v_{\max } 1651(\mathrm{C}=\mathrm{O}), 1605(\mathrm{C}=\mathrm{C}), 1450\left(\mathrm{C}=\mathrm{C}_{\mathrm{Ar}}\right), 1238(\mathrm{C}-\mathrm{O}-\mathrm{C}), 812$ (C$\left.\mathrm{H}_{\mathrm{Ar}}\right) .{ }^{1} \mathrm{H}-\mathrm{NMR}\left(\mathrm{CDCl}_{3}\right): \delta$ 1.22-1.39 $(12 \mathrm{H}, \mathrm{m}), 1.40-1.52(4 \mathrm{H}, \mathrm{m}), 1.79-1.90(4 \mathrm{H}, \mathrm{m}), 3.41(2 \mathrm{H}, \mathrm{t}, J=$ $6.8 \mathrm{~Hz}), 4.05(2 \mathrm{H}, \mathrm{t}, J=6.5 \mathrm{~Hz}), 6.30(1 \mathrm{H}, \mathrm{d}, J=6.0 \mathrm{~Hz}), 6.83(1 \mathrm{H}, \mathrm{d}, J=2.2 \mathrm{~Hz}), 6.97(1 \mathrm{H}, \mathrm{dd}, J=$ 8.9, $2.2 \mathrm{~Hz}), 7.77(1 \mathrm{H}, \mathrm{d}, J=6.0 \mathrm{~Hz}), 8.11(1 \mathrm{H}, \mathrm{d}, J=8.9 \mathrm{~Hz}) .{ }^{13} \mathrm{C}-\mathrm{NMR}\left(\mathrm{CDCl}_{3}\right): \delta 25.9\left(\mathrm{CH}_{2}\right), 28.1$ $\left(\mathrm{CH}_{2}\right), 28.7\left(\mathrm{CH}_{2}\right), 28.9\left(\mathrm{CH}_{2}\right), 29.3\left(\mathrm{CH}_{2}\right), 29.4\left(\mathrm{CH}_{2}\right), 29.5\left(\mathrm{CH}_{2}\right), 29.5\left(\mathrm{CH}_{2}\right)(\mathrm{x} 2), 32.8\left(\mathrm{CH}_{2}\right), 33.9$ $\left(\mathrm{CH}_{2}\right), 68.7\left(\mathrm{CH}_{2}\right), 100.9(\mathrm{C}), 112.9(\mathrm{C}), 114.8(\mathrm{C}), 118.6(\mathrm{C}), 127.1(\mathrm{C}), 154.8(\mathrm{C}), 158.3(\mathrm{C}), 163.7$ (C), $177.1(\mathrm{C}=\mathrm{O})$.

General procedure for the synthesis of quinoline-chalcone and quinoline-chromone hybrids

Chalcone or 8-hydroxyquinoline $(0.75 \mathrm{mmol})$, potassium hydroxide $(1 \mathrm{mmol})$ and acetonitrile $(10$ $\mathrm{mL}$ ), were placed in a $50 \mathrm{~mL}$ flat-bottomed flask equipped with a magnetic stirring bar. The mixture was stirred and heated to reflux for a period of 5 minutes, under microwave irradiation. Then, bromoalkylquinoline or bromoalkylchromenone $(0.5 \mathrm{mmol})$ was added to the reaction mixture which was then refluxed for 30 minutes $(70 \mathrm{~W})$. The crude reaction mixture was concentrated on a rotatory evaporator and the residue was purified by column chromatography over silica gel eluting with hexaneethyl acetate to obtain quinoline-chalcone or quinoline-chromone hybrids in yields ranging $44-65 \%$ and 34-70\%, respectively. Monitoring of the reaction progress and product purification was carried out by TLC.

(E)-3-(3,4-dimethoxyphenyl)-1-(4-(3-(quinolin-8-yloxy)propoxy)phenyl)prop-2-en-1-one (8): Yield 65\% (0.33 mmol, $155 \mathrm{mg})$; yellow solid, M.p. 62-64 ${ }^{\circ}$; IR $\left(\mathrm{cm}^{-1}\right): v_{\max } 1655(\mathrm{C}=\mathrm{O}), 1599(\mathrm{C}=\mathrm{C})$, 1510, $(\mathrm{C}=\mathrm{N}) 1262(\mathrm{C}-\mathrm{O}-\mathrm{C}), 803\left(\mathrm{C}-\mathrm{H}_{\mathrm{Ar}}\right) .{ }^{1} \mathrm{H}-\mathrm{NMR}\left(\mathrm{CDCl}_{3}\right): \delta$ 2.51-2.59 (2H, m), $3.94(3 \mathrm{H}, \mathrm{s}), 3.96$ $(3 \mathrm{H}, \mathrm{s}), 4.37(2 \mathrm{H}, \mathrm{t}, J=6.1 \mathrm{~Hz}), 4.48(2 \mathrm{H}, \mathrm{t}, J=6.2 \mathrm{~Hz}), 6.90(1 \mathrm{H}, \mathrm{d}, J=8.3 \mathrm{~Hz}), 7.01(2 \mathrm{H}, \mathrm{d}, J=8.8$ Hz), $7.13(1 \mathrm{H}, \mathrm{dd}, J=7.6,1.0 \mathrm{~Hz}), 7.16(1 \mathrm{H}, \mathrm{d}, J=2.0 \mathrm{~Hz}), 7.23(1 \mathrm{H}, \mathrm{dd}, \mathrm{J}=8.3,2.0), 7.37-7.49(4 \mathrm{H}$, m), $7.75(1 \mathrm{H}, \mathrm{d}, J=15.6 \mathrm{~Hz}), 8.01(2 \mathrm{H}, \mathrm{d}, J=8.8 \mathrm{~Hz}), 8.14(1 \mathrm{H}, \mathrm{dd}, J=8.3,1.7 \mathrm{~Hz}), 8.96(1 \mathrm{H}, \mathrm{dd}, J=$ 
4.4, $1.7 \mathrm{~Hz}) .{ }^{13} \mathrm{C}-\mathrm{NMR}\left(\mathrm{CDCl}_{3}\right): \delta 29.1\left(\mathrm{CH}_{2}\right), 56.0\left(\mathrm{CH}_{3}\right)(\mathrm{x} 2), 65.0\left(\mathrm{CH}_{2}\right), 65.4\left(\mathrm{CH}_{2}\right), 109.0(\mathrm{C})$, $110.2(\mathrm{C}), 111.2(\mathrm{C}), 114.3$ (C) (x2), 119.8 (C), 119.9 (C), 121.6 (C), 122.9 (C), $126.6(\mathrm{C}), 128.1$ (C), 129.5 (C), 130.7 (C) (x2), 131.3 (C), 135.9 (C), 140.4 (C), 144.0 (C), 149.2 (C), 149.3 (C), 151.3 (C), 154.6 (C), $162.6(\mathrm{C}), 188.6(\mathrm{C}=\mathrm{O})$. ESI-MS: $m / z 470.1967[\mathrm{M}+\mathrm{H}]^{+}$, Calcd for $\mathrm{C}_{29} \mathrm{H}_{27} \mathrm{NO}_{5}: 470.1959$

(E)-3-(3,4-dimethoxyphenyl)-1-(4-(4-(quinolin-8-yloxy)butoxy)phenyl)prop-2-en-1-one (9): Yield 44\% (0.22 mmol, $106.4 \mathrm{mg})$; yellow solid, M.p. $130-134^{\circ} \mathrm{C} ; \mathrm{IR}\left(\mathrm{cm}^{-1}\right)$ : $v_{\max } 1659(\mathrm{C}=\mathrm{O}), 1599(\mathrm{C}=\mathrm{C}), 1512$ $(\mathrm{C}=\mathrm{N}), 1262(\mathrm{C}-\mathrm{O}-\mathrm{C}), 814\left(\mathrm{C}-\mathrm{H}_{\mathrm{Ar}}\right) .{ }^{1} \mathrm{H}-\mathrm{NMR}\left(\mathrm{CDCl}_{3}\right): \delta$ 2.08-2.17 (2H, m), 2.20-2.29 (2H, m), 3.94 $(3 \mathrm{H}, \mathrm{s}), 3.97(3 \mathrm{H}, \mathrm{s}), 4.21(2 \mathrm{H}, \mathrm{t}, J=6.3 \mathrm{~Hz}), 4.36(2 \mathrm{H}, \mathrm{t}, J=6.4 \mathrm{~Hz}), 6.91(1 \mathrm{H}, \mathrm{d}, J=8.3 \mathrm{~Hz}), 6.99$ $(2 \mathrm{H}, \mathrm{d}, J=8.8 \mathrm{~Hz}), 7.09(1 \mathrm{H}, \mathrm{d}, J=7.6 \mathrm{~Hz}), 7.17(1 \mathrm{H}, \mathrm{d}, J=1.8 \mathrm{~Hz}), 7.24(1 \mathrm{H}, \mathrm{dd}, \mathrm{J}=8.3,1.7), 7.37-$ $7.50(4 \mathrm{H}, \mathrm{m}), 7.76(1 \mathrm{H}, \mathrm{d}, J=15.6 \mathrm{~Hz}), 8.01(2 \mathrm{H}, \mathrm{d}, J=8.9 \mathrm{~Hz}), 8.13(1 \mathrm{H}, \mathrm{dd}, J=8.3,1.9 \mathrm{~Hz}), 8.95$ $(1 \mathrm{H}, \mathrm{dd}, J=4.2,1.9 \mathrm{~Hz}) \cdot{ }^{13} \mathrm{C}-\mathrm{NMR}\left(\mathrm{CDCl}_{3}\right): \delta 25.7\left(\mathrm{CH}_{2}\right), 26.1\left(\mathrm{CH}_{2}\right), 56.0\left(\mathrm{CH}_{3}\right)(\mathrm{x} 2), 67.9\left(\mathrm{CH}_{2}\right)$, $68.5\left(\mathrm{CH}_{2}\right), 108.8(\mathrm{C}), 110.2(\mathrm{C}), 111.2(\mathrm{C}), 114.3(\mathrm{C})(\mathrm{x} 2), 119.6(\mathrm{C}), 120.0(\mathrm{C}), 121.6(\mathrm{C}), 122.9(\mathrm{C})$, 126.6 (C), 128.1 (C), 129.5 (C), 130.7 (C) (x2), 131.2 (C), 135.9 (C), 140.5 (C), 144.0 (C), 149.2 (C), 149.3 (C), $151.3(\mathrm{C}), 154.7$ (C), 162.8 (C), 188.7 (C=O). ESI-MS: m/z $484.2124[\mathrm{M}+\mathrm{H}]^{+}$, Calcd for $\mathrm{C}_{30} \mathrm{H}_{29} \mathrm{NO}_{5}: 484.2119$

(E)-3-(3,4-dimethoxyphenyl)-1-(4-((5-(quinolin-8-yloxy)pentyl)oxy)phenyl)prop-2-en-1-one (10): Yield 56\% (0.28 mmol, $139.3 \mathrm{mg})$; yellow solid, M.p. 220-224 ${ }^{\circ}$; IR $\left(\mathrm{cm}^{-1}\right): v_{\max } 1641(\mathrm{C}=\mathrm{O}), 1593(\mathrm{C}=\mathrm{C})$, $1513(\mathrm{C}=\mathrm{N}), 1221(\mathrm{C}-\mathrm{O}-\mathrm{C}), 812\left(\mathrm{C}-\mathrm{H}_{\mathrm{Ar}}\right) .{ }^{1} \mathrm{H}-\mathrm{NMR}\left(\mathrm{CDCl}_{3}\right): \delta$ 1.73-1.88 $(2 \mathrm{H}, \mathrm{m}), 1.92-2.05(2 \mathrm{H}, \mathrm{m})$, 2.11-2.24 (2H, m), $3.94(3 \mathrm{H}, \mathrm{s}), 4.01(3 \mathrm{H}, \mathrm{s}), 4.13(2 \mathrm{H}, \mathrm{t}, J=6.4 \mathrm{~Hz}), 4.32(2 \mathrm{H}, \mathrm{t}, J=6.8 \mathrm{~Hz}), 6.94$ $(1 \mathrm{H}, \mathrm{d}, J=8.5 \mathrm{~Hz}), 7.01(2 \mathrm{H}, \mathrm{d}, J=8.7 \mathrm{~Hz}), 7.11(1 \mathrm{H}, \mathrm{d}, J=7.5 \mathrm{~Hz}), 7.21(1 \mathrm{H}, \mathrm{d}, J=1.5 \mathrm{~Hz}), 7.27$ $(1 \mathrm{H}, \mathrm{dd}, \mathrm{J}=8.5,1.5), 7.37-7.53(4 \mathrm{H}, \mathrm{m}), 7.80(1 \mathrm{H}, \mathrm{d}, J=15.5 \mathrm{~Hz}), 8.06(2 \mathrm{H}, \mathrm{d}, J=8.7 \mathrm{~Hz}), 8.17(1 \mathrm{H}$, $\mathrm{dd}, J=8.2,1.1 \mathrm{~Hz}), 8.89(1 \mathrm{H}, \mathrm{dd}, J=4.0,1.1 \mathrm{~Hz}) .{ }^{13} \mathrm{C}-\mathrm{NMR}\left(\mathrm{CDCl}_{3}\right): \delta 22.8\left(\mathrm{CH}_{2}\right), 28.8\left(\mathrm{CH}_{2}\right), 29.0$ $\left(\mathrm{CH}_{2}\right), 56.0\left(\mathrm{CH}_{3}\right)(\mathrm{x} 2), 68.0\left(\mathrm{CH}_{2}\right), 68.7\left(\mathrm{CH}_{2}\right), 108.7(\mathrm{C}), 110.1(\mathrm{C}), 111.2(\mathrm{C}), 114.3(\mathrm{C})(\mathrm{x} 2), 119.6$ (C), 119.9 (C), 121.6 (C), 123.0 (C), 126.7 (C), 128.1 (C), 129.6 (C), 130.8 (C) (x2), 131.1 (C), 136.0 
(C), 140.4 (C), 144.1 (C), 149.2 (C), 149.4 (C), 151.3 (C), 154.8 (C), 162.9 (C), 188.9 (C=O). ESI-MS: $m / z$ 498.2280 $[\mathrm{M}+\mathrm{H}]^{+}$, Calcd for $\mathrm{C}_{31} \mathrm{H}_{31} \mathrm{NO}_{5}: 498.2287$

(E)-3-(3,4-dimethoxyphenyl)-1-(4-((8-(quinolin-8-yloxy)octyl)oxy)phenyl)prop-2-en-1-one (11): Yield 58\% (0.29 mmol, $156.5 \mathrm{mg})$; yellow solid, M.p. 104-108 ${ }^{\circ} \mathrm{C} ; \mathrm{IR}\left(\mathrm{cm}^{-1}\right): v_{\max } 1657(\mathrm{C}=\mathrm{O}), 1599(\mathrm{C}=\mathrm{C})$, $1513(\mathrm{C}=\mathrm{N}), 1258(\mathrm{C}-\mathrm{O}-\mathrm{C}), 816\left(\mathrm{C}-\mathrm{H}_{\mathrm{Ar}}\right) .{ }^{1} \mathrm{H}-\mathrm{NMR}\left(\mathrm{CDCl}_{3}\right): \delta 1.40-1.48(2 \mathrm{H}, \mathrm{m}), 1.48-1.54(2 \mathrm{H}, \mathrm{m})$, 1.54-1.62 (2H, m), 1.79-1.86 (2H, m), 2.01-2.09 (2H, m), $3.94(3 \mathrm{H}, \mathrm{s}), 3.96(3 \mathrm{H}, \mathrm{s}), 4.04(2 \mathrm{H}, \mathrm{t}, J=6.5$ $\mathrm{Hz}), 4.26(2 \mathrm{H}, \mathrm{t}, J=7.0 \mathrm{~Hz}), 6.90(1 \mathrm{H}, \mathrm{d}, J=8.4 \mathrm{~Hz}), 6.97(2 \mathrm{H}, \mathrm{d}, J=8.8 \mathrm{~Hz}), 7.07(1 \mathrm{H}, \mathrm{d}, J=7.6$ $\mathrm{Hz}), 7.17(1 \mathrm{H}, \mathrm{d}, J=1.9 \mathrm{~Hz}), 7.24(1 \mathrm{H}, \mathrm{dd}, \mathrm{J}=8.4,2.0), 7.36-7.48(4 \mathrm{H}, \mathrm{m}), 7.76(1 \mathrm{H}, \mathrm{d}, J=15.6 \mathrm{~Hz})$, $8.03(2 \mathrm{H}, \mathrm{d}, J=8.9 \mathrm{~Hz}), 8.12(1 \mathrm{H}, \mathrm{dd}, J=8.3,1.7 \mathrm{~Hz}), 8.96(1 \mathrm{H}, \mathrm{dd}, J=4.1,2.0 \mathrm{~Hz}) .{ }^{13} \mathrm{C}-\mathrm{NMR}$ $\left(\mathrm{CDCl}_{3}\right): \delta 25.9\left(\mathrm{CH}_{2}\right), 26.0\left(\mathrm{CH}_{2}\right), 29.0\left(\mathrm{CH}_{2}\right), 29.1\left(\mathrm{CH}_{2}\right), 29.2\left(\mathrm{CH}_{2}\right), 29.3\left(\mathrm{CH}_{2}\right), 56.0\left(\mathrm{CH}_{3}\right)(\mathrm{x} 2)$, $68.2\left(\mathrm{CH}_{2}\right), 69.0\left(\mathrm{CH}_{2}\right), 108.6(\mathrm{C}), 110.2(\mathrm{C}), 111.2(\mathrm{C}), 114.3(\mathrm{C})(\mathrm{x} 2), 119.4(\mathrm{C}), 119.9(\mathrm{C}), 121.5$ (C), 122.9 (C), 126.6 (C), 128.1 (C), 129.5 (C), 130.7 (C) (x2), $131.1(\mathrm{C}), 135.8$ (C), 140.5 (C), 144.0 (C), 149.2 (C), 149.3 (C), 151.3 (C), 154.7 (C), 162.9 (C), 188.7 (C=O). ESI-MS: $m / z$, 540.2750 [M + $\mathrm{H}]^{+}$, Calcd for $\mathrm{C}_{34} \mathrm{H}_{37} \mathrm{NO}_{5}: 540.2742$.

(E)-3-(3,4-dimethoxyphenyl)-1-(4-((9-(quinolin-8-yloxy)nonyl)oxy)phenyl)prop-2-en-1-one (12): Yield 49\% (0.23 mmol, $127.4 \mathrm{mg})$; yellow solid, M.p. 84-88 ${ }^{\circ}$; IR $\left(\mathrm{cm}^{-1}\right): v_{\max } 1728(\mathrm{C}=\mathrm{O}), 1655(\mathrm{C}=\mathrm{C})$, $1601(\mathrm{C}=\mathrm{N}), 1262(\mathrm{C}-\mathrm{O}-\mathrm{C}), 797\left(\mathrm{C}-\mathrm{H}_{\mathrm{Ar}}\right) .{ }^{1} \mathrm{H}-\mathrm{NMR}\left(\mathrm{CDCl}_{3}\right): \delta 1.35-1.51(8 \mathrm{H}, \mathrm{m}), 1.52-1.65(2 \mathrm{H}, \mathrm{m})$, 1.76-1.90 (2H, m), 2.01-2.13 (2H, m), $3.95(3 \mathrm{H}, \mathrm{s}), 3.98(3 \mathrm{H}, \mathrm{s}), 4.05(2 \mathrm{H}, \mathrm{t}, J=6.5 \mathrm{~Hz}), 4.26(2 \mathrm{H}, \mathrm{t}, J$ $=7.1 \mathrm{~Hz}), 6.91(1 \mathrm{H}, \mathrm{d}, J=8.3 \mathrm{~Hz}), 6.99(2 \mathrm{H}, \mathrm{d}, J=8.8 \mathrm{~Hz}), 7.08(1 \mathrm{H}, \mathrm{d}, J=7.5 \mathrm{~Hz}), 7.19(1 \mathrm{H}, \mathrm{d}, J=$ $1.5 \mathrm{~Hz}), 7.26(1 \mathrm{H}, \mathrm{dd}, \mathrm{J}=8.3,1.6), 7.36-7.51(4 \mathrm{H}, \mathrm{m}), 7.79(1 \mathrm{H}, \mathrm{d}, J=15.5 \mathrm{~Hz}), 8.06(2 \mathrm{H}, \mathrm{d}, J=8.8$ $\mathrm{Hz}), 8.14(1 \mathrm{H}, \mathrm{dd}, J=8.3,1.4 \mathrm{~Hz}), 8.97(1 \mathrm{H}, \mathrm{dd}, J=4.2,1.5 \mathrm{~Hz}) .{ }^{13} \mathrm{C}-\mathrm{NMR}\left(\mathrm{CDCl}_{3}\right): \delta 26.0\left(\mathrm{CH}_{2}\right)$, $26.1\left(\mathrm{CH}_{2}\right), 29.0\left(\mathrm{CH}_{2}\right), 29.1\left(\mathrm{CH}_{2}\right), 29.3\left(\mathrm{CH}_{2}\right), 29.4\left(\mathrm{CH}_{2}\right), 29.5\left(\mathrm{CH}_{2}\right), 56.0\left(\mathrm{CH}_{3}\right)(\mathrm{x} 2), 68.3\left(\mathrm{CH}_{2}\right)$, $69.0\left(\mathrm{CH}_{2}\right), 108.6(\mathrm{C}), 110.1(\mathrm{C}), 111.1(\mathrm{C}), 114.3(\mathrm{C})(\mathrm{x} 2), 119.4(\mathrm{C}), 119.9(\mathrm{C}), 121.6(\mathrm{C}), 123.0(\mathrm{C})$, 126.7 (C), 128.1 (C), 129.5 (C), 130.8 (C) (x2), 131.6 (C), 135.9 (C), 140.4 (C), 144.0 (C), 149.2 (C), 
149.3 (C), 151.2 (C), 154.9 (C), 163.0 (C), 188.8 (C=O). ESI-MS: m/z 554.2987 [M + H] $]^{+}$, Calcd for $\mathrm{C}_{35} \mathrm{H}_{39} \mathrm{NO}_{5}: 554.2991$.

(E)-3-(3,4-dimethoxyphenyl)-1-(4-((12-(quinolin-8-yloxy)dodecyl)oxy)phenyl)prop-2-en-1-one

(13):

Yield 51\% (0.26 mmol, $155 \mathrm{mg})$; yellow solid, M.p. 98-102 ${ }^{\circ}$; IR $\left(\mathrm{cm}^{-1}\right): v_{\max } 1656(\mathrm{C}=\mathrm{O}), 1599$ $(\mathrm{C}=\mathrm{C}), 1503(\mathrm{C}=\mathrm{N}), 1258(\mathrm{C}-\mathrm{O}-\mathrm{C}), 801\left(\mathrm{C}-\mathrm{H}_{\mathrm{Ar}}\right) .{ }^{1} \mathrm{H}-\mathrm{NMR}\left(\mathrm{CDCl}_{3}\right): \delta$ 1.27-1.49 (14H, m), 1.50-1.64 $(2 \mathrm{H}, \mathrm{m}), 1.75-1.93(2 \mathrm{H}, \mathrm{m}), 2.01-2.15(2 \mathrm{H}, \mathrm{m}), 3.98(3 \mathrm{H}, \mathrm{s}), 4.01(3 \mathrm{H}, \mathrm{s}), 4.08(2 \mathrm{H}, \mathrm{t}, J=6.7 \mathrm{~Hz}), 4.28$ $(2 \mathrm{H}, \mathrm{t}, J=7.1 \mathrm{~Hz}), 6.94(1 \mathrm{H}, \mathrm{d}, J=8.4 \mathrm{~Hz}), 7.02(2 \mathrm{H}, \mathrm{d}, J=8.8 \mathrm{~Hz}), 7.10(1 \mathrm{H}, \mathrm{d}, J=7.5 \mathrm{~Hz}), 7.21$ $(1 \mathrm{H}, \mathrm{d}, J=1.5 \mathrm{~Hz}), 7.28(1 \mathrm{H}, \mathrm{dd}, \mathrm{J}=8.3,1.7), 7.38-7.53(4 \mathrm{H}, \mathrm{m}), 7.80(1 \mathrm{H}, \mathrm{d}, J=15.7 \mathrm{~Hz}), 8.07(2 \mathrm{H}$, $\mathrm{d}, J=8.8 \mathrm{~Hz}), 8.16(1 \mathrm{H}, \mathrm{dd}, J=8.3,1.6 \mathrm{~Hz}), 8.99(1 \mathrm{H}, \mathrm{dd}, J=4.2,1.6 \mathrm{~Hz}) .{ }^{13} \mathrm{C}-\mathrm{NMR}\left(\mathrm{CDCl}_{3}\right): \delta 26.0$ $\left(\mathrm{CH}_{2}\right), 26.1\left(\mathrm{CH}_{2}\right), 29.0\left(\mathrm{CH}_{2}\right), 29.1\left(\mathrm{CH}_{2}\right), 29.4\left(\mathrm{CH}_{2}\right), 29.5\left(\mathrm{CH}_{2}\right), 29.6\left(\mathrm{CH}_{2}\right)(\mathrm{x} 4), 56.0\left(\mathrm{CH}_{3}\right)(\mathrm{x} 2)$, $68.3\left(\mathrm{CH}_{2}\right), 69.0\left(\mathrm{CH}_{2}\right), 108.6(\mathrm{C}), 110.1(\mathrm{C}), 111.1(\mathrm{C}), 114.3(\mathrm{C})(\mathrm{x} 2), 119.4(\mathrm{C}), 119.9(\mathrm{C}), 121.6$ (C), 123.0 (C), 126.7 (C), $128.1(\mathrm{C}), 129.5$ (C), 130.8 (C) (x2), $131.1(\mathrm{C}), 135.9$ (C), 140.5 (C), 144.1 (C), 149.2 (C), 149.3 (C), 151.2 (C), 154.9 (C), 163.0 (C), 188.8 (C=O). ESI-MS: $m / z 596.3410$ [M + $\mathrm{H}]^{+}$, Calcd for $\mathrm{C}_{38} \mathrm{H}_{45} \mathrm{NO}_{5}: 596.3404$.

7-[4-(quinolin-8-yloxy)butoxy]-4H-chromen-4-one (20): Yield 34\% (0.17 mmol, $61.4 \mathrm{mg}$ ); yellow solid, M.p. $160-164^{\circ} \mathrm{C}$; IR $\left(\mathrm{cm}^{-1}\right): v_{\max } 1641(\mathrm{C}=\mathrm{O}), 1593(\mathrm{C}=\mathrm{C}), 1565(\mathrm{C}=\mathrm{N}), 1437\left(\mathrm{C}=\mathrm{C}_{\mathrm{Ar}}\right), 1267(\mathrm{C}-$ O-C), $820\left(\mathrm{C}-\mathrm{H}_{\mathrm{Ar}}\right) .{ }^{1} \mathrm{H}-\mathrm{NMR}\left(\mathrm{CDCl}_{3}\right): \delta 2.10-2.19(2 \mathrm{H}, \mathrm{m}), 2.20-2.29(2 \mathrm{H}, \mathrm{m}), 4.23(2 \mathrm{H}, \mathrm{t}, J=6.2 \mathrm{~Hz})$, $4.36(2 \mathrm{H}, \mathrm{t}, J=6.2 \mathrm{~Hz}), 6.27(1 \mathrm{H}, \mathrm{d}, J=6.0 \mathrm{~Hz}), 6.85(1 \mathrm{H}, \mathrm{d}, J=2.3 \mathrm{~Hz}), 6.94(1 \mathrm{H}, \mathrm{dd}, J=9.0,2.3$ Hz), $7.08(1 \mathrm{H}, \mathrm{d}, J=7.6 \mathrm{~Hz}), 7.36-7.48(3 \mathrm{H}, \mathrm{m}), 7.76(1 \mathrm{H}, \mathrm{d}, J=6.0 \mathrm{~Hz}), 8.07(1 \mathrm{H}, \mathrm{d}, J=9.0 \mathrm{~Hz})$, $8.12(1 \mathrm{H}, \mathrm{dd}, J=8.3,1.5 \mathrm{~Hz}), 8.94(1 \mathrm{H}, \mathrm{dd}, J=4.1,1.5 \mathrm{~Hz}) .{ }^{13} \mathrm{C}-\mathrm{NMR}\left(\mathrm{CDCl}_{3}\right): \delta 25.6\left(\mathrm{CH}_{2}\right), 26.2$ $\left(\mathrm{CH}_{2}\right), 68.4\left(\mathrm{CH}_{2}\right), 68.5\left(\mathrm{CH}_{2}\right), 100.1(\mathrm{C}), 108.7(\mathrm{C}), 112.9(\mathrm{C}), 114.8(\mathrm{C}), 118.6(\mathrm{C}), 119.7(\mathrm{C}), 121.5$ $\left(\mathrm{C}_{1}\right), 126.6(\mathrm{C}), 127.1(\mathrm{C}), 129.5(\mathrm{C}), 135.8(\mathrm{C}), 140.4(\mathrm{C}), 149.3(\mathrm{C}), 154.6(\mathrm{C}), 154.7(\mathrm{C}), 158.2(\mathrm{C})$, $163.5(\mathrm{C}), 176.9(\mathrm{C}=\mathrm{O})$. ESI-MS: $m / z 362.1392[\mathrm{M}+\mathrm{H}]^{+}$, Calcd for $\mathrm{C}_{22} \mathrm{H}_{19} \mathrm{NO}_{4}: 362.1390$ 
7-\{[5-(quinolin-8-yloxy)pentyl]oxy\}-4H-chromen-4-one (21):Yield $61 \%$ (0.31 mmol, $116.4 \mathrm{mg})$;

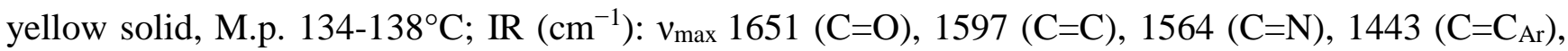
$1263(\mathrm{C}-\mathrm{O}-\mathrm{C}), 824\left(\mathrm{C}-\mathrm{H}_{\mathrm{Ar}}\right) .{ }^{1} \mathrm{H}-\mathrm{NMR}\left(\mathrm{CDCl}_{3}\right): \delta 1.73-1.81(2 \mathrm{H}, \mathrm{m}), 1.92-2.01(2 \mathrm{H}, \mathrm{m}), 2.08-2.17(2 \mathrm{H}$, m), $4.02(2 \mathrm{H}, \mathrm{t}, J=6.4 \mathrm{~Hz}), 4.29(2 \mathrm{H}, \mathrm{t}, J=6.7 \mathrm{~Hz}), 6.26(1 \mathrm{H}, \mathrm{d}, J=6.1 \mathrm{~Hz}), 6.81(1 \mathrm{H}, \mathrm{d}, J=2.4 \mathrm{~Hz})$, $6.94(1 \mathrm{H}, \mathrm{dd}, J=8.8,2.4 \mathrm{~Hz}), 7.07(1 \mathrm{H}, \mathrm{d}, J=7.8 \mathrm{~Hz}), 7.36-7.47(3 \mathrm{H}, \mathrm{m}), 7.76(1 \mathrm{H}, \mathrm{d}, J=6.1 \mathrm{~Hz})$, $8.09(1 \mathrm{H}, \mathrm{d}, J=8.8 \mathrm{~Hz}), 8.12(1 \mathrm{H}, \mathrm{dd}, J=8.3,1.6 \mathrm{~Hz}), 8.94(1 \mathrm{H}, \mathrm{dd}, J=4.2,1.6 \mathrm{~Hz}) .{ }^{13} \mathrm{C}-\mathrm{NMR}$ $\left(\mathrm{CDCl}_{3}\right): \delta 22.8\left(\mathrm{CH}_{2}\right), 28.7\left(\mathrm{CH}_{2}\right), 28.8\left(\mathrm{CH}_{2}\right), 68.4\left(\mathrm{CH}_{2}\right), 68.7\left(\mathrm{CH}_{2}\right), 100.9(\mathrm{C}), 108.7(\mathrm{C}), 112.9$ (C), 114.8 (C), 118.6 (C), 119.6 (C), 121.5 (C), 126.6 (C), 127.1 (C), 129.5 (C), 135.8 (C), 140.5 (C), 149.3 (C), 154.7 (C), 154.8 (C), 158.2 (C), 163.6 (C), $177.0(\mathrm{C}=\mathrm{O})$. ESI-MS: m/z 376.1549 [M + H] $]^{+}$ Calcd for $\mathrm{C}_{23} \mathrm{H}_{21} \mathrm{NO}_{4}: 376.1542$.

7-\{[8-(quinolin-8-yloxy)octyl]oxy\}-4H-chromen-4-one (22): Yield 70\% (0.35 mmol, $146.1 \mathrm{mg})$; yellow solid, M.p. $110-114^{\circ} \mathrm{C}$; IR $\left(\mathrm{cm}^{-1}\right): v_{\max } 1655(\mathrm{C}=\mathrm{O}), 1593(\mathrm{C}=\mathrm{C}), 1593(\mathrm{C}=\mathrm{N}), 1443(\mathrm{C}=\mathrm{C}$ Ar $), 1263(\mathrm{C}-$ O-C), $818\left(\mathrm{C}-\mathrm{H}_{\mathrm{Ar}}\right) .{ }^{1} \mathrm{H}-\mathrm{NMR}\left(\mathrm{CDCl}_{3}\right): \delta$ 1.42-1.54 $(2 \mathrm{H}, \mathrm{m}), 1.55-1.67(2 \mathrm{H}, \mathrm{m}), 1.80-1.93(2 \mathrm{H}, \mathrm{m})$, 2.02-2.19 (2H, m), $4.07(2 \mathrm{H}, \mathrm{t}, J=6.6 \mathrm{~Hz}), 4.28(2 \mathrm{H}, \mathrm{t}, J=7.0 \mathrm{~Hz}), 6.31(1 \mathrm{H}, \mathrm{d}, J=6.1 \mathrm{~Hz}), 6.85(1 \mathrm{H}$, $\mathrm{d}, J=2.3 \mathrm{~Hz}), 7.01(1 \mathrm{H}, \mathrm{dd}, J=8.9,2.3 \mathrm{~Hz}), 7.10(1 \mathrm{H}, \mathrm{d}, J=7.5 \mathrm{~Hz}), 7.38-7.53(3 \mathrm{H}, \mathrm{m}), 7.80(1 \mathrm{H}, \mathrm{d}$, $J=6.0 \mathrm{~Hz}), 8.13(1 \mathrm{H}, \mathrm{d}, J=8.7 \mathrm{~Hz}), 8.16(1 \mathrm{H}, \mathrm{dd}, J=8.0,1.4 \mathrm{~Hz}), 8.99(1 \mathrm{H}, \mathrm{dd}, J=4.2,1.4 \mathrm{~Hz}) .{ }^{13} \mathrm{C}-$ NMR $\left(\mathrm{CDCl}_{3}\right): \delta 25.9\left(\mathrm{CH}_{2}\right), 26.0\left(\mathrm{CH}_{2}\right), 28.9\left(\mathrm{CH}_{2}\right), 29.0\left(\mathrm{CH}_{2}\right), 29.2\left(\mathrm{CH}_{2}\right), 29.3\left(\mathrm{CH}_{2}\right), 68.7\left(\mathrm{CH}_{2}\right)$, $68.9\left(\mathrm{CH}_{2}\right), 100.8(\mathrm{C}), 108.6(\mathrm{C}), 112.9(\mathrm{C}), 114.9(\mathrm{C}), 118.6(\mathrm{C}), 119.4(\mathrm{C}), 121.6(\mathrm{C}), 126.7(\mathrm{C})$, 127.2 (C), 129.5 (C), 136.0 (C), 140.4 (C), 149.3 (C), 154.7 (C), 154.9 (C), 158.3 (C), 163.7 (C), 177.1 $(\mathrm{C}=\mathrm{O})$. ESI-MS: $m / z$ 418.2127 [M + H] $]^{+}$, Calcd for $\mathrm{C}_{26} \mathrm{H}_{27} \mathrm{NO}_{4}: 418.2123$.

7-\{[9-(quinolin-8-yloxy)nonyl]oxy\}-4H-chromen-4-one (23): Yield 36\% (0.18 mmol, 77.7 mg); yellow solid, M.p. 93-95 C; IR ( $\left.\mathrm{cm}^{-1}\right): v_{\max } 1659(\mathrm{C}=\mathrm{O}), 1626(\mathrm{C}=\mathrm{C}), 1594(\mathrm{C}=\mathrm{N}), 1381\left(\mathrm{C}=\mathrm{C}_{\mathrm{Ar}}\right), 1265(\mathrm{C}-$ O-C), $818\left({\left.\mathrm{C}-\mathrm{H}_{\mathrm{Ar}}\right) .}^{1} \mathrm{H}-\mathrm{NMR}\left(\mathrm{CDCl}_{3}\right): \delta\right.$ 1.31-1.45 $(6 \mathrm{H}, \mathrm{m}), 1.45-1.51(2 \mathrm{H}, \mathrm{m}), 1.51-1.60(2 \mathrm{H}, \mathrm{m})$, $1.78-1.86(2 \mathrm{H}, \mathrm{m}), 2.01-2.08(2 \mathrm{H}, \mathrm{m}), 4.03(2 \mathrm{H}, \mathrm{t}, J=6.5 \mathrm{~Hz}), 4.25(2 \mathrm{H}, \mathrm{t}, J=6.9 \mathrm{~Hz}), 6.27(1 \mathrm{H}, \mathrm{d}, J=$ 
$6.0 \mathrm{~Hz}), 6.82(1 \mathrm{H}, \mathrm{d}, J=2.3 \mathrm{~Hz}), 6.96(1 \mathrm{H}, \mathrm{dd}, J=8.9,2.3 \mathrm{~Hz}), 7.07(1 \mathrm{H}, \mathrm{d}, J=7.8 \mathrm{~Hz}), 7.36-7.48$ $(3 \mathrm{H}, \mathrm{m}), 7.76(1 \mathrm{H}, \mathrm{d}, J=6.0 \mathrm{~Hz}), 8.11(1 \mathrm{H}, \mathrm{dd}, J=8.1,1.0 \mathrm{~Hz}), 8.13(1 \mathrm{H}, \mathrm{d}, J=8.5 \mathrm{~Hz}), 8.96(1 \mathrm{H}, \mathrm{dd}$, $J=4.2,1.4 \mathrm{~Hz}) .{ }^{13} \mathrm{C}-\mathrm{NMR}\left(\mathrm{CDCl}_{3}\right): \delta 25.9\left(\mathrm{CH}_{2}\right), 26.0\left(\mathrm{CH}_{2}\right), 28.9\left(\mathrm{CH}_{2}\right), 29.0\left(\mathrm{CH}_{2}\right), 29.2\left(\mathrm{CH}_{2}\right)$, $29.3\left(\mathrm{CH}_{2}\right), 29.4\left(\mathrm{CH}_{2}\right), 68.7\left(\mathrm{CH}_{2}\right), 69.0\left(\mathrm{CH}_{2}\right), 100.8(\mathrm{C}), 108.6(\mathrm{C}), 112.9(\mathrm{C}), 114.8(\mathrm{C}), 118.6(\mathrm{C})$, 119.3 (C), 121.5 (C), 126.6 (C), 127.1 (C), 129.5 (C), 135.9 (C), 140.4 (C), 149.2 (C), 154.7 (C), 154.9 (C), 158.2 (C), 163.7 (C), $177.0(\mathrm{C}=\mathrm{O})$. ESI-MS: $m / z$ 432.2175 [M + H] $]^{+}$, Calcd for $\mathrm{C}_{27} \mathrm{H}_{29} \mathrm{NO}_{4}$ : 432.2173.

7-\{[12-(quinolin-8-yloxy)dodecyl]oxy\}-4H-chromen-4-one (24):Yield 61\% (0.31 mmol, $146.8 \mathrm{mg})$; yellow solid, M.p. 98-100 C; IR $\left(\mathrm{cm}^{-1}\right): v_{\max } 1651(\mathrm{C}=\mathrm{O}), 1622(\mathrm{C}=\mathrm{C}), 1596(\mathrm{C}=\mathrm{N}), 1441\left(\mathrm{C}=\mathrm{C}_{\mathrm{Ar}}\right)$, $1263(\mathrm{C}-\mathrm{O}-\mathrm{C}), 817\left(\mathrm{C}-\mathrm{H}_{\mathrm{Ar}}\right) .{ }^{1} \mathrm{H}-\mathrm{NMR}\left(\mathrm{CDCl}_{3}\right): \delta$ 1.24-1.43 (12H, m), 1.44-1.50 (2H, m), 1.51-1.60 $(2 \mathrm{H}, \mathrm{m}), 1.78-1.87(2 \mathrm{H}, \mathrm{m}), 1.99-2.08(2 \mathrm{H}, \mathrm{m}), 4.04(2 \mathrm{H}, \mathrm{t}, J=6.6 \mathrm{~Hz}), 4.24(2 \mathrm{H}, \mathrm{t}, J=7.1 \mathrm{~Hz}), 6.27$ $(1 \mathrm{H}, \mathrm{d}, J=6.1 \mathrm{~Hz}), 6.82(1 \mathrm{H}, \mathrm{d}, J=2.1 \mathrm{~Hz}), 6.96(1 \mathrm{H}, \mathrm{dd}, J=8.8,2.0 \mathrm{~Hz}), 7.06(1 \mathrm{H}, \mathrm{d}, J=7.7 \mathrm{~Hz})$, 7.34-7.48 (3H, m), $7.76(1 \mathrm{H}, \mathrm{d}, J=6.1 \mathrm{~Hz}), 8.10(1 \mathrm{H}, \mathrm{dd}, J=8.1,1.2 \mathrm{~Hz}), 8.12(1 \mathrm{H}, \mathrm{d}, J=8.2 \mathrm{~Hz})$, $8.95(1 \mathrm{H}, \mathrm{dd}, J=4.2,1.2 \mathrm{~Hz}) .{ }^{13} \mathrm{C}-\mathrm{NMR}\left(\mathrm{CDCl}_{3}\right): \delta 25.9\left(\mathrm{CH}_{2}\right), 26.0\left(\mathrm{CH}_{2}\right), 28.9\left(\mathrm{CH}_{2}\right), 29.0\left(\mathrm{CH}_{2}\right)$, $29.3\left(\mathrm{CH}_{2}\right), 29.41\left(\mathrm{CH}_{2}\right), 29.47\left(\mathrm{CH}_{2}\right), 29.48\left(\mathrm{CH}_{2}\right), 29.49\left(\mathrm{CH}_{2}\right), 29.5\left(\mathrm{CH}_{2}\right), 68.7\left(\mathrm{CH}_{2}\right), 69.0\left(\mathrm{CH}_{2}\right)$, 100.9 (C), $108.6(\mathrm{C}), 112.9$ (C), 114.8 (C), 118.6 (C), 119.3 (C), 121.5 (C), 126.6 (C), 127.1 (C), 129.5 (C), 135.8 (C), 140.5 (C), 149.2 (C), 154.7 (C), 154.9 (C), 158.3 (C), 163.7 (C), 177.0 (C=O). ESI-MS: $m / z 474.2644[\mathrm{M}+\mathrm{H}]^{+}$, Calcd for $\mathrm{C}_{30} \mathrm{H}_{35} \mathrm{NO}_{4}: 474.2642$.

\section{Biological activity assays}

The compounds were subjected to evaluation of in vitro cytotoxicity on U937 human cells and leishmanicidal and trypanocidal activities on intracellular amastigotes of L. (V) panamensis and T. cruzi. 
In vitro Cytotoxicity

The cytotoxic activity of the compounds was assessed based on the viability of the human promonocytic cell line U-937 (ATCC CRL-1593.2 ${ }^{\mathrm{TM}}$ ) evaluated by the MTT (3-(4,5-dimethylthiazol2-yl)-2,5-diphenyltetrazolium bromide) assay following the methodology described previously (Taylor et al., 2011). Briefly, cells grown in tissue flasks were harvested and washed with phosphate buffered saline (PBS) by centrifuging. Cells were counted and adjusted at $1 \times 10^{6}$ cells $/ \mathrm{mL}$ of RPMI-1640 supplemented with complete $10 \%$ Fetal Bovine Serum (FBS) and 1\% antibiotics (100 U/mL penicillin and $0.1 \mathrm{mg} / \mathrm{mL}$ streptomycin). One hundred $\mu \mathrm{L}$ were dispensed into each well of a 96-well cell-culture plate and then $100 \mathrm{~mL}$ of RPMI-1640 and the corresponding concentrations of the compounds were added, starting at $200 \mu \mathrm{g} / \mathrm{mL}$ in duplicate. Plates were incubated at $37{ }^{\circ} \mathrm{C}, 5 \% \mathrm{CO}_{2}$ during $72 \mathrm{~h}$ in the presence of extracts. The effect of compounds was determined by measuring the activity of the mitochondrial dehydrogenase by adding $10 \mu \mathrm{L} /$ well of MTT solution $(0.5 \mathrm{mg} / \mathrm{mL})$ and incubation at 37 ${ }^{\circ} \mathrm{C}$ for $3 \mathrm{~h}$. The reaction was stopped by adding $100 \mu \mathrm{L} /$ well of $50 \%$ isopropanol solution with $10 \%$ sodium dodecyl sulfate and 30 min incubation. Cell viability was determined based on the quantity of formazan produced according to the intensity of color (absorbance) registered as optical densities (O.D) obtained at $570 \mathrm{~nm}$ in a spectrophotometer (Varioskan ${ }^{\mathrm{TM}}$ Flash Multimode Reader - Thermo Scientific, USA). Cells cultured in absence of compounds were used as control of viability (negative control), while meglumine antimoniate (Sbv) and amphotericin B (AmB) were used as control for cytotoxicity (non-cytotoxic and cytotoxic drugs, respectively). Assays were conducted in two independent runs with three replicates per each concentration tested.

In vitro leishmanicidal activity

The activity of compounds was evaluated on intracellular amastigotes of L. (V) panamensis transfected with the green fluorescent protein gene (MHOM/CO/87/UA140pIR-GFP) (Pulido et al., 
2012). The effect of each extract was determined according to the inhibition of the infection evidenced by both decrease of the infected cells and decrease of intracellular parasite load. Briefly, U-937 human cells at a concentration of $3 \times 10^{5}$ cells/mL in RPMI 1640 and $0.1 \mu \mathrm{g} / \mathrm{mL}$ of phorbol-12-myristate-13acetate (PMA) were dispensed into each well of a 24-well cell culture plate and then infected with 5 days-old promastigotes in a 15:1 parasites per cell ratio. Plates were incubated at $34{ }^{\circ} \mathrm{C}, 5 \% \mathrm{CO}_{2}$ during $3 \mathrm{~h}$ and cells were washed two times with PBS to eliminate not internalized parasites. One mL of fresh RPMI 1640 supplemented with 10\% FBS and 1\% antibiotics was added into each well, cells were incubated again to guarantee multiplication of intracellular parasites. After $24 \mathrm{~h}$ of infection, culture medium was replaced by fresh culture medium containing each compound at $20 \mu \mathrm{g} / \mathrm{mL}$ or lower (based on the cytotoxicity showed previously by each compound) and plates were incubated at $37{ }^{\circ} \mathrm{C}, 5 \%$ $\mathrm{CO}_{2}$. After $72 \mathrm{~h}$, inhibition of the infection was determined. For this, cells were removed from the bottom plate with a trypsin/EDTA $(250 \mathrm{mg})$ solution; recovered cells were centrifuged at $1100 \mathrm{rpm}$ during 10 min at $4{ }^{\circ} \mathrm{C}$, the supernatant was discarded and cells were washed with $1 \mathrm{~mL}$ of cold PBS and centrifuged at $1100 \mathrm{rpm}$ during $10 \mathrm{~min}$ at $4{ }^{\circ} \mathrm{C}$. The supernatant was discarded and cells were suspended in $500 \mu \mathrm{L}$ of PBS and analyzed by flow cytometry (FC 500MPL, Cytomics, Brea, CA, US. All determinations for each extract and standard drugs were carried out in triplicate, in two independent experiments (Buckner et al., 1996; Pulido et al., 2012). Activity of tested extracts was carried out in parallel with infection progress in culture medium alone and in culture medium with AmB and Sbv as antileishmanial drugs (positive controls). Compounds that showed percentages of inhibition higher than $50 \%$ to 20 or fewer $\mu \mathrm{g} / \mathrm{mL}$ were then evaluated at four additional concentrations to determine the effective concentration $50\left(\mathrm{EC}_{50}\right)$. Here, infected cells were exposed against each concentration of compounds during $72 \mathrm{~h}$; then, cells were removed and tested by flow cytometry as described before. 
In vitro Trypanocidal Activity

Compounds were tested on intracellular amastigotes of $T$. cruzi, Tulahuen strain transfected with $\beta$ galactosidase gene (donated by Dr. F. S. Buckner, University of Washington) (Buckner et al., 1996). The activity was determined according to the ability of the extract to reduce the infection of U-937 cells by $T$. cruzi as described elsewhere (Insuasty et al., 2015). Following the procedure described above, anti-T. cruzi activity was initially screened at a single concentration of $20 \mathrm{mg} / \mathrm{mL}$. In this case, $100 \mu \mathrm{L}$ of U-937 human cells at a concentration of $2.5 \times 10^{5}$ cells/mL in RPMI-1640, $10 \%$ SFB and 0.1 $\mu \mathrm{g} / \mathrm{mL}$ of PMA were placed in each well of 96-well plates and then infected with phase growth epimastigotes in 5:1 (parasites per cell) ratio and incubated at $34{ }^{\circ} \mathrm{C}, 5 \% \mathrm{CO}_{2}$. After 24 hours of incubation, $20 \mu \mathrm{g} / \mathrm{mL}$ of each extract were added to infected cells. After $72 \mathrm{~h}$ of incubation, the effect of all extracts on viability of intracellular amastigotes was determined by measuring the $\beta$-galactosidase activity by spectrophotometry adding $100 \mu \mathrm{M}$ CPRG and $0.1 \%$ nonidet P-40 to each well. After $3 \mathrm{~h}$ of incubation, plates were read at $570 \mathrm{~nm}$ in a spectrophotometer (Varioskan ${ }^{\mathrm{TM}}$ Flash Multimode Reader Thermo Scientific, USA) and intensity of color (absorbance) was registered as O.D. Extracts that showed inhibition percentages higher than $50 \%$ were evaluated again at four concentrations selected according to the $\mathrm{LC}_{50}$ previously obtained for each compound. Infected cells exposed to benznidazol (BNZ) were used as control for antitrypanosomal activity (positive control) while infected cells incubated in culture medium alone were used as control for infection (negative control). Non-specific absorbance was corrected by subtracting the O.D of the blank. Determinations were done by triplicate in at least two independent experiments (Insuasty et al., 2015). 


\begin{abstract}
Statistical Analysis
Cytotoxicity was determined according to the percentages of viability and mortality registered to each compound an concentration, including amphotericin $\mathrm{B}$, meglumine antimoniate and culture medium alone. Percentage of viability was calculated by Equation 1, where the O.D of control, corresponds to $100 \%$ of viability.
\end{abstract}

$$
\% \text { Viability }=(\text { O.D Exposed cells }) /(\text { O.D Control cells }) \times 100
$$

In turn, mortality percentage corresponds to $100 \%-\%$ viability.

Results were expressed as 50 lethal concentrations $\left(\mathrm{LC}_{50}\right)$ that corresponds to the concentration necessary to eliminate $50 \%$ of cells and calculated by Probit analysis (Finney, 1978). The degree of toxicity was graded according to the $\mathrm{LC}_{50}$ value using the following scale: high cytotoxicity: $\mathrm{LC}_{50}<$ $100 \mu \mathrm{g} / \mathrm{mL}$; moderate cytotoxicity: $\mathrm{LC}_{50}>100$ to $<200 \mu \mathrm{g} / \mathrm{mL}$ and potentially non-cytotoxicity: $\mathrm{LC}_{50}>$ $200 \mu \mathrm{g} / \mathrm{mL}$.

On the other hand, anti-leishmanial activity was determined according to the percentage of infected cells and parasite load, obtained for each experimental condition by flow cytometry. The percentage of infected cells was determined as the number of positive events evidenced by green fluorescence (parasites) and Forward Scatter (FSC) using dotplot analysis, while, the parasitic load was determined by analysis of mean fluorescence intensity (MFI) of fluorescent parasites (Pulido et al., 2012). The parasite inhibition was calculated by equation 2, where the MFI of control, corresponds to $100 \%$ of parasites.

$$
\% \text { Parasite }=(\text { MFI Exposed parasites }) /(\text { MFI Control parasites }) \times 100
$$

In turn, inhibition percentage corresponds to $100 \%-\%$ Parasites. Results of leishmanicidal activity were expressed as $\mathrm{EC}_{50}$ determined by the Probit analysis (Finney, 1978). 
Similarly, trypanocidal activity was determined according to the percentage of infected cells and parasite load obtained for each experimental condition by colorimetry. Parasite inhibition was calculated by equation 3 , where the O.D of control corresponds to $100 \%$ of infection.

$$
\% \text { Infection }=(\text { O.D Exposed parasites }) /(\text { O.D Control parasites }) \times 100
$$

In turn, percentage of inhibition of infection corresponds to $100 \%$ - \% of Infection.

Results of anti-leishmanial and anti-trypanocidal activities were expressed as $\mathrm{EC}_{50}$ determined by the Probit analysis (Finney, 1978). The leishmanicidal or trypanocidal activities were graded according to the $\mathrm{EC}_{50}$ value using the following scale: High activity: $\mathrm{EC}_{50}<25 \mu \mathrm{g} / \mathrm{mL}$, moderate activity: $\mathrm{EC}_{50}>25$ to $<50 \mu \mathrm{g} / \mathrm{mL}$; potentially non activity: $\mathrm{EC}_{50}>50 \mu \mathrm{g} / \mathrm{mL}$.

The selectivity index (SI), was calculated by dividing the cytotoxic activity and the leishmanicidal or trypanocidal activity using the following formula: $\mathrm{SI}=\mathrm{CL}_{50} / \mathrm{CE}_{50}$. Cytotoxic compound: $\mathrm{LC}_{50}<100$ $\mu \mathrm{g} / \mathrm{mL}$.

\section{Results and discussion}

Chemistry

Quinoline-chalcone hybrids 8-13 were obtained via microwave assisted Williamson etherification (Peng et al., 2002; Otero et al., 2014) between bromoalkylquinoline 2-7 and 3,4-dimethoxy-4'hydroxychalcone. Reaction yields ranged between $44 \%$ and $65 \%$. Chalcone was prepared using a previously described method (Peyman et al., 2004) (Scheme 1). Compounds 2-7 were obtained using the same method from 8-hydroxyquinoline and dibromoalkanes with different numbers of carbon atoms with yields between $51 \%$ and $80 \%$. 
Quinoline-chromone hybrids were obtained following the same synthetic strategy (Scheme 1). Initially, 7-hydroxychromone was treated with potassium hydroxide and 1, $\omega$-dibromoalkanes $(\omega=3$, 4, 5, 7, 9 and 12) to obtain the respective bromoalkyl derivatives $\mathbf{1 5 - 1 9}$ in yields similar to previous reports (Otero et al., 2014; Li et al., 2013) but in significantly shorter times. These compounds were coupled with quinoline to produce compounds 20-24 in 34-70\% yields. Remarkably, low yields were obtained when bromoalkylquinoline analogues were used as tactical variants.
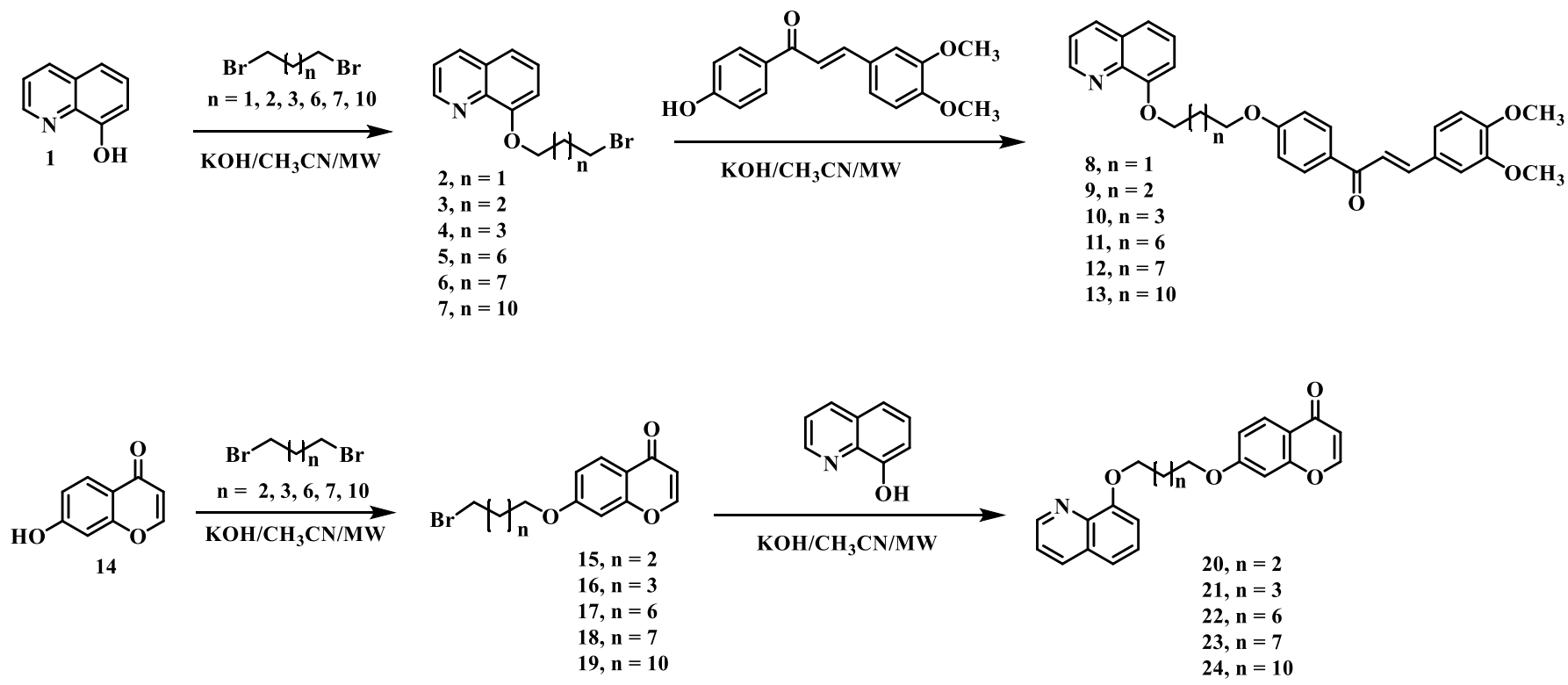

Scheme 1 Synthetic pathway to quinoline-chalcone and quinoline-chromone hybrids. 
Leishmanicidal, trypanocidal and cytotoxic activities

The effect of quinoline-chalcone and quinolone-chromone hybrids on cell growth and viability was assessed in human macrophages (U-937 cells) (Pulido et al., 2012) which are the host cells for L. (V) panamensis and T. cruzi parasites. On the other hand, the antiparasite activity of these compounds was tested on intracellular amastigotes of L. (V.) panamensis (Taylor et al., 2011) and T. cruzi (Buckner et al., 1996; Insuasty et al., 2015) according to the ability of these compounds to reduce the amount of parasite inside infected macrophages. Results are summarized in the Table 1. 
Table 1 In vitro cytotoxicity and antiprotozoal activity of quinoline-chalcone and quinoline-chromone hybrids

\begin{tabular}{|c|c|c|c|c|c|}
\hline \multirow{2}{*}{ Compound } & & \multicolumn{2}{|l|}{ Leishmanicidal activity } & \multicolumn{2}{|l|}{ Trypanocidal activity } \\
\hline & $\mathrm{LC}_{50}{ }^{\mathrm{a}}$ & $\mathrm{EC}_{50}{ }^{\mathrm{b}}$ & $\mathrm{SI}^{\mathrm{c}}$ & $\mathrm{EC}_{50}$ & SI \\
\hline 8 & $39.6 \pm 1.5,84.34$ & $11.79 \pm 0.34,25.11$ & 3.36 & $35.08 \pm 4.17,74.71$ & 1.13 \\
\hline 9 & $16.1 \pm 0.9,33.29$ & $6.24 \pm 0.14,12.90$ & 2.58 & $17.62 \pm 1.56,36.44$ & 0.91 \\
\hline 10 & $23.5 \pm 2.4,47.23$ & $12.37 \pm 0.93,24.86$ & 1.90 & $15.79 \pm 1.47,31.73$ & 1.49 \\
\hline 11 & $16.7 \pm 1.4,30.94$ & $8.53 \pm 0.69,15.81$ & 1.96 & $37.61 \pm 4.07,69.69$ & 0.44 \\
\hline 12 & $>40,72.24$ & $16.41 \pm 2.47,29.64$ & $>2.43$ & $15.12 \pm 1.75,27.30$ & $>2.64$ \\
\hline 13 & $69.2 \pm 9.3,116.15$ & $22.0 \pm 4.47,36.93$ & 3.15 & $54.95 \pm 5.47,92.23$ & 1.26 \\
\hline 20 & $5.4 \pm 0.9,14.94$ & $6.11 \pm 0.26,16.91$ & 0.89 & $4.09 \pm 0.24,11.32$ & 1.33 \\
\hline 21 & $113.5 \pm 16.3,302.33$ & $48.29 \pm 8.18,128.63$ & 2.35 & $40.70 \pm 7.40,108.41$ & 2.79 \\
\hline 22 & $121.4+9.3,290.77$ & $21.54 \pm 6.47,51.59$ & 5.64 & $28.43 \pm 2.77,68.09$ & 4.27 \\
\hline 23 & $4.1 \pm 0.2,9.50$ & $7.35 \pm 1.15,17.03$ & 0.56 & $>2,>4.63$ & $<2$ \\
\hline 24 & $71.9 \pm 8.9,151.81$ & $16.18 \pm 1.45,34.16$ & 4.89 & $>20,>42.23$ & $<3.95$ \\
\hline $\begin{array}{l}\text { 3,4-dimethoxy-4'- } \\
\text { hydroxychalcone }\end{array}$ & $4.1 \pm 0.3,14.42$ & $2.36 \pm 0.37,8.30$ & 1.75 & $>2,>7.03$ & $<2$ \\
\hline 8-hydroxyquinoline (1) & $0.2 \pm 0.01,1.38$ & $0.36 \pm 0.02,2.48$ & 0.62 & $0.34 \pm 0.07,2.34$ & 0.66 \\
\hline 7-hydroxychromone (14) & $132.5 \pm 25.7,814.11$ & $116.49 \pm 13.27,718.45$ & 1.14 & $18.23 \pm 2.62,112.43$ & 7.27 \\
\hline Meglumine antimoniate & $416.4 \pm 66.6$ & $9.4 \pm 2.1$ & 44.3 & $\mathrm{NA}^{\mathrm{d}}$ & $\mathrm{NA}^{\mathrm{d}}$ \\
\hline Amphotericin B & $42.1 \pm 2.0,45.6$ & $0.05 \pm 0.01,0.054$ & 842 & $\mathrm{NA}^{\mathrm{d}}$ & $\mathrm{NA}^{\mathrm{d}}$ \\
\hline Benznidazole & $179.0 \pm 4.2,687.8$ & $\mathrm{NA}^{\mathrm{d}}$ & $\mathrm{NA}^{\mathrm{d}}$ & $10.5 \pm 1.8,40.3$ & 17.0 \\
\hline
\end{tabular}

Data represent mean value +/- standard deviation; ${ }^{a} \mathrm{LC}_{50}$ : Lethal Concentration $50 \mathrm{in} \mu \mathrm{g} / \mathrm{mL}, \mu \mathrm{M}$; ${ }^{\mathrm{b}} \mathrm{EC}_{50}$ : Effective Concentration 50 in $\mu \mathrm{g} / \mathrm{mL}, \mu \mathrm{M}$; ${ }^{\mathrm{c}}$ SI: Selectivity Index $=\mathrm{LC}_{50} / \mathrm{EC}_{50} ;{ }^{\mathrm{d}} \mathrm{NA}$ : Not applicable. Active compounds: $\mathrm{EC}_{50}$ $<25 \mu \mathrm{g} / \mathrm{mL}$ 
All compounds, amphotericin B and benznidazole with exception of 21, 22 and chromone, were highly cytotoxic to U-937 cells showing $\mathrm{LC}_{50}<100.0 \mu \mathrm{g} / \mathrm{mL}$ (Table 1). Compounds 21,22 and chromone, showed moderate cytotoxicity evidenced by $\mathrm{LC}_{50}$ values higher than $100.0 \mu \mathrm{g} / \mathrm{mL}$. In turn, meglumine antimoniate showed no cytotoxicity $\left(\mathrm{LC}_{50}>200.0 \mu \mathrm{g} / \mathrm{mL}\right)$.

The anti-leishmanial and anti-trypanocidal activities were measured by determining the effective concentration $50\left(\mathrm{EC}_{50}\right)$ that corresponds to the concentration of drug that gives the half-maximal reduction of the amount of intracellular parasites (Table 1). Dose-response relationship showed that compounds 8-12, 20, 23, 24, chalcone and quinoline were highly active against intracellular amastigotes of $L$. $(V)$ panamensis with $\mathrm{EC}_{50}<20 \mu \mathrm{g} / \mathrm{mL}$. The most actives hybrids compounds were 20, 9, 23 and 11 with an $\mathrm{EC}_{50}$ of $6.11 \pm 0.26 \mu \mathrm{g} / \mathrm{mL}(16.91 \mu \mathrm{M}), 6.24 \pm 0.14 \mu \mathrm{g} / \mathrm{mL}(12.90 \mu \mathrm{M}), 7.35$ $\pm 1.15 \mu \mathrm{g} / \mathrm{mL}(17.03 \mu \mathrm{M})$ and $8.53 \pm 0.69 \mu \mathrm{g} / \mathrm{mL}(15.81 \mu \mathrm{M})$ respectively, followed by $\mathbf{8}, \mathbf{1 0}, \mathbf{1 2}$ and 24 with an $\mathrm{EC}_{50}$ of $11.79 \pm 0.34 \mu \mathrm{g} / \mathrm{mL}(25.11 \mu \mathrm{M}), 12.37 \pm 0.93 \mu \mathrm{g} / \mathrm{mL}(24.86 \mu \mathrm{M}), 16.41 \pm 2.47$ $\mu \mathrm{g} / \mathrm{mL}, 29.64 \mu \mathrm{M} 16.18 \pm 1.45 \mu \mathrm{g} / \mathrm{mL}(34.16 \mu \mathrm{M})$. As expected, the leishmanicidal drugs amphotericin $\mathrm{B}$ and meglumine antimoniate showed activity with low $\mathrm{EC}_{50}$ values.

In turn, compounds 20, 23, chalcone and quinoline were highly active against intracellular amastigotes of $T$. cruzi with $\mathrm{EC}_{50}$ of $4.09 \pm 0.24 \mu \mathrm{g} / \mathrm{mL}(11.32 \mu \mathrm{M}),>2 \mu \mathrm{g} / \mathrm{mL}(>4.63 \mu \mathrm{M}),>2 \mu \mathrm{g} / \mathrm{mL}$ $(>7.03 \mu \mathrm{M}) 0.34 \pm 0.07 \mu \mathrm{g} / \mathrm{mL}(2.34 \mu \mathrm{M})$ respectively, followed by compounds $\mathbf{9}, \mathbf{1 0}, \mathbf{1 2}$ and chromone with an $\mathrm{EC}_{50}$ of $17.62 \pm 1.56 \mu \mathrm{g} / \mathrm{mL}(36.44 \mu \mathrm{M}), 15.79 \pm 1.47 \mu \mathrm{g} / \mathrm{mL}(31.73 \mu \mathrm{M}), 15.12 \pm$ $1.75 \mu \mathrm{g} / \mathrm{mL}(27.30 \mu \mathrm{M})$ and $18.23 \pm 2.62 \mu \mathrm{g} / \mathrm{mL}(112.43 \mu \mathrm{M})$ respectively. In this case, benznidazole showed activity with an $\mathrm{EC}_{50}$ of $10.5 \pm 1.8 \mu \mathrm{g} / \mathrm{mL}(40.3 \mu \mathrm{M})$. 
The anti-leishmanial activity of compounds $\mathbf{8 - 1 3}, \mathbf{2 1}, \mathbf{2 2}, \mathbf{2 4}$, chalcone and chromone and antitrypanocidal activity of compounds $\mathbf{8}, \mathbf{1 0}, \mathbf{1 2}, \mathbf{1 3}, \mathbf{2 0 - 2 4}$ and chromone were higher than their cytotoxicity. Thus, the SI (Selectivity Index) values calculated for these compounds were $>1$ (Table 1).

As demonstrated elsewhere, amphotericin B and meglumine antimoniate have very high SI values. Although all hybrid compounds showed better activity than meglumine antimoniate and the antitrypanocidal activity of compounds $\mathbf{2 0}$ and $\mathbf{2 3}$ were higher than benznidazole, the SI of these compounds is affected by their high cytotoxicity. These results suggest that biological activity of the quinoline derivatives reported here, with exception of $\mathbf{2 0}$ and $\mathbf{2 3}$, is selective, being more active against L. (V) panamensis than U-937 cells. On the other hand, compounds $\mathbf{8}, \mathbf{1 0}, \mathbf{1 2}, \mathbf{1 3}, \mathbf{2 0 - 2 4}$ were more actives against $T$. cruzi parasites than U-937 cells.

There is not a clear relationship between the antiprotozoal activity and the length of the alkyl linker, because as the chain length increase (increased lipophilicity), the activity does not show a definite tendency. All quinoline-chalcone hybrids were less cytotoxic and less active than the parent subunits. However, a synergistic effect of the parent subunits was observed in the quinoline-chromone hybrids in comparison with the unlinked cases, due to decreased cytotoxicity based on quinoline and increased activity based chromone. One possible mechanism of action for these compounds may be formulated in terms of conjugated addition of nucleophilic amino acid residues present in target enzymes of Leishmania e.g. such cysteine proteases (Mottram et al., 2004) in a Michael addition (Cardona et al., 2014). 


\section{Conclusion}

The synthesis, anti-leishmanial and anti-trypanocidal screening of eleven quinoline derivatives are reported. Several of the synthetic compounds have potential as templates for drugs development. Eight of them were active against $L .(V)$ panamensis $(\mathbf{8 - 1 2}, \mathbf{2 0}, \mathbf{2 3}$ and 24) and five of them against $T$. cruzi $\left(\mathbf{9}, \mathbf{1 0}, \mathbf{1 2}, \mathbf{2 0}\right.$ and 23) with $\mathrm{EC}_{50}$ values lower than $18 \mu \mathrm{g} / \mathrm{mL}, \mathbf{2 0}$ being the most active compound for both L. (V) panamensis and T. cruzi. All hybrid compounds showed better activity than meglumine antimoniate and compounds $\mathbf{2 0}$ and $\mathbf{2 3}$ showed higher actives than benznidazole. Studies on an animal model of leishmaniasis are needed to confirm the results observed in vitro. These compounds were toxic for mammalian U-937 cells, however they may still have potential to be considered as candidates to antileishmanial drug development. More studies on toxicity using other cell lines are needed to discriminate whether the toxicity shown by these compounds is specific against tumor or non-tumor cells. Moreover, Michael acceptor moieties may modify the parasitic activity and cytotoxicity. The mechanism of action of these promising compounds also needs to be addressed.

\section{Acknowledgments}

The authors thank Universidad de Antioquia (grant CODI IN656CE and CIDEPRO) for financial support.

\section{Conflict of interest}

The authors declare that they have no conflict of interest. 


\section{References}

Alvar J, Vélez ID, Bern C, Herrero M, Desjeux P, Cano J, Jannin J, den Boer M (2012) Leishmaniasis Worldwide and Global Estimates of Its Incidence. PLOS One 7: e35671

Baloch N, Alkahraman Y, Zaidi M, Madkour H (2012) Evaluation of 6, 8-Dichloro-2-Methyl-4HChromen-4-One Derivatives as Antileishmanial Agents. Global J Sci Front Res Chem 12:1-7

Bhutta ZA, Sommerfeld J, Lassi ZS, Salam RA, Das JK (2014) Tackling the existing burden of infection diseases in the developing world: existing gaps and the way forward. Infect Dis Poverty 3: $1-6$

Boeck P, Bandeira Falcão CA, Leal PC, Yones RA, Filho VC, Torres-Santos EC, Rossi-Bergmann B (2006) Synthesis of chalcone analogues with increased antileishmanial activity. Bioorg Med Chem 14:1538-1545

Buckner FS, Verlinde CL, La Flamme AC, Van Voorhis WC (1996) Efficient technique for screening drugs for activity against Trypanosoma cruzi using parasites expressing beta-galactosidase. Antimicrob Agents Chemother 40: 2592-2597

Cardona W, Arango V, Domínguez J, Robledo S, Muñoz D, Figadère B, Velez ID, Sáez, J (2013) Synthesis and leishmanicidal activity of new bis-alkylquinolines. J Chil Chem Soc 58:1709-1712

Cardona W, Guerra D, Restrepo A (2014) Reactivity of $\delta$-substituted $\alpha, \beta$-unsaturated cyclic lactones with antileishmanial activity. Mol Simul 40:477-484

Chatelain E, Ioset JR (2011) Drug discovery and development for neglected diseases: the DNDi model. Drug Des Devel Ther 16:175-181

Chen M, Zhai L, Christensen SB, Theander TG, Kharazmi A (2001) Inhibition of fumarate reductase in Leishmania major and L. donovani by chalcones. Antimicrobiol. Agents Chemother. 45:20232029

Coa JC, Castrillón W, Cardona W, Carda M, Ospina V, Muñoz JA, Vélez ID, Robledo SM (2015) 
Synthesis, leishmanicidal, trypanocidal and cytotoxic activity of quinoline-hydrazone hybrids. Eur J Med Chem 101:746-753

Den Boer M, Argaw D, Jannin J, Alvar J (2011) Leishmaniasis impact and treatment access. Clin Microbiol Infect 17:1471-1477

Dietze R, Carvalho SF, Valli LC, Berman J, Brewer T, Milhous W, Sanchez J, Schuster B, Grogl M (2001) Phase 2 trial of WR6026, an orally administered 8-aminoquinoline, in the treatment of visceral leishmaniasis caused by Leishmania chagasi. Am J Trop Med Hyg 65:685-689

Ellis GP, Barker G (1972) Chromone-2- and -3-carboxylic acids and their derivatives. Progr Med Chem 9:65-116

Finney JD (1978) Probit Analysis: Statistical Treatment of the Sigmoid Response Curve, $3^{\text {rd }}$ ed.; Cambridge University Press: Cambridge, UK, p. 550.

Franck X, Fournet A, Prina E, Mahieux R, Hocquemiller R, Figadère B (2004) Biological evaluation of substituted quinolones. Bioorg Med Chem Lett 14:3635-3638

Hadjeri M, Barbier M, Ronot X, Mariotte AM, Boumendjel A, Boutonnat J (2003) Modulation of Pglycoprotein-mediated multidrug resistance by flavonoid derivatives and analogues. J Med Chem $46: 2125-2131$

Horton DA, Boume GT, Smythe ML (2003). The combinatorial synthesis of bicyclic privileged structures or privileged substructures. Chem Rev 103:893-930

Houghton PJ (2000) Chemistry and biological activity of natura land semi-synthetic 450 chromone alkaloids. Stud Nat Prod Chem 21:123-155

Insuasty B, Ramirez J, Becerra D, Echeverry C, Quiroga J, Abonia R, Robledo SM, Velez ID, Upegui Y, Muñoz JA, Ospina V, Nogueras M, Cobo J (2015). An efficient synthesis of a new caffeine-based chalcones, pyrazolines and pyrazolo[3-4-b][1-4]diazepines as potential antimalarial, 
antitrypanosomal and antileishmanial agents. Eur J Chem Med 93:401-413

Kayser O, Kiderlen AF (2001) In vitro leishmanicidal activity of naturally occurring chalcones.

Phytother Res 15:148-152

Keenan M, Chaplin JH (2015) A new era for chagas disease drug discovery?, Prog Med Chem 54:

$185-230$

Li SY, Wang XB, Xie SS, Jian N, Wang KD, Yao HQ, Sun HB, Kong LY (2013)

Multifunctional tacrine-flavonoid hybrids with cholinergic, $\beta$-amyloid-reducing, and metal chelating properties for the treatment of Alzheimer's disease. Eur J Med Chem 69:632-646

Liu M, Wilairat P, Croft SL, Tand AL, Go ML (2003) Structure-activity relationships of antileishmanial and antimalarial chalcones. Bioorg Med Chem 11: 2729-2738

Mallick S, Dutta A, Ghosh J, Maiti S, Mandal AK, Banerjee R, Bandyopadhyay C, Pal C (2011)

Protective therapy with novel chromone derivative against Leishmania donovani infection induces

Th1 response in vivo. Chemotherapy 57:388-393

Mohammed AF, Fournet A, Prina E, Mouscadet JF, Franck X, Hocquemiller R, Figadère B, Fakhfakh MA (2003) Synthesis and biological evaluation of substituted quinolines: potential treatment of protozoal and retroviral co-infections. Bioorg Med Chem 11:5013-5023

Mottram JC, Coombs GH, Alexander J (2004) Cysteine peptidases as virulence factors of Leishmania. Curr Opin Microbiol 7:375-381

Nakayama H, Loiseau PM, Bories C, De Ortiz ST, Schinini A, Serna E, Rojas de Arias A, Fakhfakh MA, Franck X, Figadère B, Hocquemiller R, Fournet A (2005) Efficacy of orally administered 2substituted quinolines in experimental murine cutaneous and visceral leishmaniases. Antimicrob. Agents Chemother 49 :4950-4956

Nouvellet P, Cucunubá ZM, Gourbière S (2015) Ecology, evolution and control of Chagas disease: a century of neglected modelling and promising future. Adv Parasitol 87:135-191 
Otero E, Vergara S, Robledo SM, Cardona W, Carda M, Vélez ID, Rojas C, Otálvaro F (2014)

Synthesis, Leishmanicidal and Cytotoxic Activity of Triclosan-Chalcone, Triclosan-Chromone and Triclosan-Coumarin Hybrids. Molecules 19:13251-13266

Palit P, Paira P, Hazra A, Banerjee S, Das Gupta A, Dastidar S, Mondal N (2009) Phase transfer catalyzed synthesis of bis-quinolines: antileishmanial activity in experimental visceral leishmaniasis and in vitro antibacterial evaluation. Eur J Med Chem 44:845-853

Peng Y, Song G (2002) Combined microwave and ultrasound assisted Williamson ether synthesis in the absence of phase-transfer catalysts. Green Chem 4:349-351.

Peyman S, Minoo D, Mohammad AZ, Mohammad AB (2004) Silica Sulfuric Acid as an Efficient and Reusable Reagent for Crossed-Aldol Condensation of Ketones with Aromatic Aldehydes under Solvent-Free Conditions. J Braz Chem Soc 15:773-776

Pulido SA, Muñoz DL, Restrepo AM, Mesa CV, Alzate JF, Vélez ID, Robledo SM (2012) Improvement of the green fluorescent protein reporter system in Leishmania spp. for the in vitro and in vivo screening of antileishmanial drugs. Acta Trop 122:36-45

Suresh K, Sandhya B, Himanshu G (2009) Biological activities of quinoline derivatives. Mini-Rev Med Chem 9: 1648-1654

Taylor VM, Cedeño DL, Muñoz DL, Jones MA, Lash TD, Young AM, Constantino MH, Esposito N, Vélez ID, Robledo SM (2011) In vitro and in vivo studies of the utility of dimethyl and diethyl carbaporphyrin ketals in treatment of cutaneous leishmaniasis. Antimicrob Agents Chemother $55: 4755-4764$

Tempone A, Melo A, Da Silva P, Brandt C, Martinez F, Borborema A (2005) Synthesis and antileishmanial activities of novel 3-substituted quinolones. Agents chemother 49:1076-1080 

Vieira NC, Herrenknecht C, Vacus J, Fournet A, Bories C, Figadère B, Espindola LS, Loiseau PM (2008) Selection of the most promising 2-substituted quinoline as antileishmanial candidate for clinical trials. Biomed Pharmacother 62:684-689

World Health Organization. Why are some tropical diseases called 'neglected'? http://www.who.int/features/qa/58/en/, 2013 [accessed 04.12.13]. 